\title{
Adherence, persistence, and medication discontinuation in patients with attention-deficit/ hyperactivity disorder - a systematic literature review
}

Neuropsychiatric Disease and Treatment

22 August 2014

Number of times this article has been viewed

\author{
Kavita Gajria' \\ Mei Lu² \\ Vanja Sikirica' \\ Peter Greven ${ }^{3,4}$ \\ Yichen Zhong ${ }^{2}$ \\ Paige Qin ${ }^{2}$ \\ Jipan $\mathrm{Xie}^{2}$
}

'Global Health Economics, Outcomes Research and Epidemiology, Shire, Wayne, PA, USA; ${ }^{2}$ Health Economics and Outcomes Research, Analysis Group, Inc., Boston, MA, USA; ${ }^{3}$ Institute of Child and Adolescent Psychiatry, Psychotherapy and Social Pediatrics, Berlin, Germany; ${ }^{4}$ Department of Psychology and Mental Health, H:G University of Health and Sport, Technology and Arts, Berlin, Germany
Correspondence:Vanja Sikirica Global Health Economics, Outcomes Research and Epidemiology, Shire, 725 Chesterbrook Boulevard,Wayne, PA 19087, USA

Tel + I4845958579

Email vsikirica@shire.com
Abstract: Untreated attention-deficit/hyperactivity disorder (ADHD) can lead to substantial adverse social, economic, and emotional outcomes for patients. The effectiveness of current pharmacologic treatments is often reduced, due to low treatment adherence and medication discontinuation. This current systematic literature review analyzes the current state of knowledge surrounding ADHD medication discontinuation, focusing on: 1) the extent of patient persistence; 2) adherence; and 3) the underlying reasons for patients' treatment discontinuation and how discontinuation rates and reasons vary across patient subgroups. We selected 91 original studies (67 with persistence/discontinuation results, 26 with adherence results, and 41 with reasons for discontinuation, switching, or nonadherence) and 36 expert opinion reviews on ADHD medication discontinuation, published from 1990 to 2013. Treatment persistence on stimulants, measured by treatment duration during the 12-month follow-up periods, averaged 136 days for children and adolescents and 230 days for adults. Owing to substantial study heterogeneity, comparisons across age or medication type subgroups were generally inconclusive; however, long-acting formulations and amphetamines were associated with longer treatment duration than short-acting formulations and methylphenidates. The medication possession ratio, used to measure adherence, was $<0.7$ for all age groups and medication classes during a 12-month period. Adverse effects were the most commonly cited reason for discontinuation in all studies. Original research studies reported the lack of symptom control as a common discontinuation reason, followed by dosing inconvenience, social stigma associated with ADHD medication, and the patient's attitude. In summary, although there was a lack of consistency in the measurement of adherence and persistence, these findings indicate that drug adherence and persistence are generally poor among patients with ADHD. Clinicians may be able to help improve adherence and persistence to ADHD treatment by educating caregivers and patients on treatment goals, administering long-acting medications, and following-up with patients to verify if medication is still effective and well-tolerated.

Keywords: treatment discontinuation, adherence, persistence, ADHD medication, literature review

\section{Introduction}

Attention-deficit/hyperactivity disorder (ADHD) is a common psychiatric disorder characterized by hyperactivity, impulsivity, and difficulty maintaining sustained attention. ${ }^{1}$ Approximately $5.3 \%$ of children and adolescents are affected by ADHD worldwide, ${ }^{2}$ of whom $60 \%$ continue to demonstrate notable ADHD symptoms throughout life. ${ }^{3}$ 
Pharmacologic treatment is a key component of evidencebased care for patients with ADHD and has been shown to be a cost-effective therapeutic option. ${ }^{4}$ Currently, there are two main classes of medications with proven efficacy for ADHD - stimulants and nonstimulants. Stimulants, such as amphetamines (AMPHs) and methylphenidates (MPHs), have been the mainstay of ADHD pharmacotherapy. ${ }^{5}$ For patients with contraindications, or those who are averse or nonresponsive to stimulants, nonstimulants, such as guanfacine extended release (GXR), atomoxetine (ATX), and clonidine hydrochloride extended release, are alternative treatment options.

Owing to the chronic nature of ADHD symptoms, patients with ADHD typically require long-term pharmacotherapy. Despite the demonstrated effectiveness of current ADHD medications, treatment discontinuation is fairly common. One-half of all patients fail to adhere to treatment guidelines ${ }^{6}$ or discontinue treatment within 2-3 years of starting pharmacologic therapy. ${ }^{7,8}$ Such behaviors may be associated with suboptimal control of ADHD symptoms, ${ }^{9}$ increasing the likelihood of serious deleterious effects that can accrue and escalate over time. ${ }^{10}$ These include social and academic difficulties, behavioral problems such as substance abuse, delinquency, accidental injury, ${ }^{11,12}$ and poor economic, social, and emotional well-being. ${ }^{12,13}$ Such consequences impact patients as well as their families and communities.

The decision to discontinue treatment can be associated with a variety of factors, including patient characteristics, patient or caregiver choice, medication-related factors (eg, duration of action, risk-benefit profile, etc), and practitionerrelated or health system-related factors. ${ }^{14,15}$ Although the literature exists on reasons for ADHD treatment discontinuation, a comprehensive review of these studies synthesizing the underlying issues surrounding discontinuation (particularly for specific ADHD populations, medication classes, and geographic locations) could facilitate the design of programs to improve treatment adherence and subsequent patient health outcomes, and would benefit both researchers and providers. This study aimed to meet this need by conducting a systematic literature review of real-world observational studies and review articles of expert opinions on medication discontinuation among patients with ADHD. In particular, the study sought to accomplish three objectives: 1) to explore the extent of patient persistence on (or discontinuation of) ADHD treatment; 2) to examine patient adherence to various ADHD medications; and 3) to evaluate the underlying reasons for patients' treatment discontinuation. Variations of discontinuation rates, adherence, and reasons for treatment discontinuation were analyzed across subgroups of patients by age group, geographic location, and medication class.

\section{Materials and methods Systematic literature search}

A systematic literature review was performed on October 11, 2013, by searching four main electronic databases via the OvidSP $^{16}$ interface: MedLine ${ }^{17}$ (including In-Process and Other Non-Indexed Citations, January 1990-September 2013); EMBASE ${ }^{18}$ (January 1990-September 2013); PsycINFO $^{19}$ (January 1990-September 2013); and Cochrane Database of Systematic Reviews ${ }^{20}$ (January 2005-July 2013). The four sets of search terms used were: disease of interest (terms for "attention-deficit hyperactivity disorder"); selected medication treatments (terms listed in Table S1); treatment discontinuation (terms for discontinuation, adherence, or persistence); and eligible study types (terms for retrospective or observational studies). Publications retrieved from the search were screened using the inclusion and exclusion criteria detailed in Table 1, and this review followed the reporting guidelines recommended by Preferred Reporting Items for Systematic Reviews and Meta-Analyses (PRISMA). ${ }^{21}$

Publications were screened at two levels. At the level I screening, inclusion/exclusion criteria were applied at the title/abstract level. At the level II screening, the full text of each article was reviewed against the selection criteria. The reason for its exclusion was recorded for each article failing level I or level II screening. To ensure complete capture of all relevant studies, the bibliographies of all reviews and meta-analysis articles were examined during level II screening to identify any additional original studies previously not included (via the snowballing technique). ${ }^{22}$ Reviews and meta-analyses were included for data extraction if they reported expert opinions and/or were not based on original studies. Two researchers conducted the level I and level II screenings independently; a third researcher was consulted to arbitrate disagreements over study inclusions when needed.

Multiple publications (kin studies) arising from the same research study (primary publications) were identified based on the study sample, research team, analytical method, and results, and linked to avoid duplication. Information was extracted from the primary study and, if available, additional information from the kin studies was also extracted and combined with the primary study. Because we sought to understand the nature of all of the available literature on these topics, the scientific quality of the published studies was not assessed in this systematic literature review. 
Table I Selection criteria of systematic review

\begin{tabular}{|c|c|}
\hline Inclusion criteria & $\begin{array}{l}\text { Publication type } \\
\text { - Full-text primary publications of real-world studies } \\
\text { - Treatment guidelines for US, Canada, UK, Germany, France, Spain, Italy, Sweden, and the Netherlands - as well } \\
\text { as any general European guidelines } \\
\text { - Editorials and commentaries } \\
\text { - Reviews (systematic and nonsystematic) and meta-analyses of real-world studies } \\
\text { Study design of real-world studies } \\
\text { - Observational studies based on real-world data (cohort studies, including both prospective and retrospective } \\
\text { designs, cross-sectional studies, and case-control studies) } \\
\text { - Phase IV clinical trials } \\
\text { Population } \\
\text { - At least } 80 \% \text { of study population (children, adolescents, or adults) have ADHD as the primary disorder } \\
\text { Interventions } \\
\text { - ADHD drug treatment approved as of September } 2013 \text { by a regulatory agency in North America or Europe for } \\
\text { ADHD in monotherapy or in combination therapy, ie: } \\
\text { O Stimulants: MPH, AMPH/dexamphetamine, and lisdexamfetamine } \\
\text { - Nonstimulants: ATX, GXR, and clonidine extended release } \\
\text { Two off-label medications commonly used in ADHD: } \\
\text { O GIR and CIR } \\
\text { Outcomes } \\
\text { - Reported discontinuation/switching results, or } \\
\text { - Reported reasons for discontinuation/switching of ADHD drug treatment } \\
\text { Language: English }\end{array}$ \\
\hline Exclusion criteria & $\begin{array}{l}\text { Publication type } \\
\text { - Nonprimary publications of real-world studies (eg, a publication that has less data than the primary publication } \\
\text { to report the same outcomes) } \\
\text { - Conference abstracts or posters } \\
\text { - Congress proceedings } \\
\text { - Books/chapters/addresses/bibliographies/biographies/lectures } \\
\text { - Case reports } \\
\text { - Letters } \\
\text { - Treatment guidelines for countries other than: US, Canada, UK, Germany, France, Spain, Italy, Sweden, and the } \\
\text { Netherlands } \\
\text { - Reviews/meta-analyses not of real-world studies } \\
\text { Study design } \\
\text { - Preclinical studies } \\
\text { - Clinical trials (Phase I-Phase III) } \\
\text { - Prognostic studies } \\
\text { - Genetic studies } \\
\text { Population } \\
\text { - Nonhuman subjects } \\
\text { - Not ADHD patients } \\
\text { - < } 80 \% \text { of study population have ADHD as the primary disorder } \\
\text { Intervention } \\
\text { - No drug treatment } \\
\text { - Drug treatment not listed in the inclusion criteria } \\
\text { Outcomes } \\
\text { - Does not report discontinuation/continuation results, and } \\
\text { - Does not report reasons for ADHD medication discontinuation } \\
\text { Language: Non-English } \\
\text { Publication date: Before I } 990\end{array}$ \\
\hline
\end{tabular}

Abbreviations: ADHD, attention-deficit/hyperactivity disorder; MPH, methylphenidate; AMPH, amphetamine; ATX, atomoxetine; GXR, guanfacine extended release; GIR, guanfacine immediate release; CIR, clonidine immediate release.

\section{Data extraction}

For original research articles meeting the selection criteria, study-level specifics, methodology, and discontinuation data were extracted. Study-level specifics consisted of publication details, study type, data source, participant characteristics, medications of interest, and the geographic location of the study population. Methodology-related data included the patient selection criteria and the time frame for outcome 
measurement in each specific study. Discontinuation data included definitions of measures, estimates, and reasons (including nonadherence and switching), if available.

For publications reporting expert opinions (reviews, meta-analyses, editorials/commentaries, and treatment guidelines), geographic location, study population, treatment(s) of interest, and reasons and recommendations for medication discontinuation were recorded.

\section{Data synthesis}

Data were synthesized for the following three outcomes: 1) persistence/discontinuation; 2) adherence; and 3 ) reasons for discontinuation (including nonadherence and switching). Persistence was evaluated for patients remaining on therapy and was defined as the time between treatment initiation and discontinuation, while adherence was generally defined based on the proportion of time a patient took a prescribed ADHD medication according to its dosage schedule.

A qualitative summary was constructed for persistence/ discontinuation studies based on pharmacy refill records/ databases, as well as on patient and parent/caregiver surveys. A quantitative analysis was performed using data that originated from the subset of persistence/discontinuation studies that implemented comparable measure definitions and follow-up periods. For various patient subgroups, pooled estimates of treatment duration were calculated as the weighted average across studies by sample size. These pooled estimates were then compared by patient age group, medication class (stimulants versus nonstimulants), formulation (long-acting [LA] versus short-acting [SA]), and stimulant type (AMPH versus MPH).

A qualitative summary was constructed for the adherence studies (pharmacy refill records/databases, patient and parent/caregiver surveys, and physician assessments) using the level or percentage of patients classified as adherent to ADHD medications. For the subset of adherence studies using comparable measure definitions and follow-up periods, a quantitative analysis was conducted by computing average adherence rates for patient subgroups weighted by sample size. Pooled treatment durations were then compared by age group, medication class, formulation, and stimulant type.

It should be noted that, when interpreting persistence and adherence to medication in the child/adolescent population, drug holidays, which refers to being temporarily off the prescribed medication during nonschool days, should be taken into consideration. Persistence and adherence might be underestimated when their measures were defined without considering drug holidays.
Qualitative summaries were constructed to display the treatment discontinuation reasons extracted from original research and expert opinion articles. Reasons for discontinuation were reported from the patients', parent/caregivers', and clinicians' perspectives and were compared by age group, medication class, and geographic location. The summary encompassed a broad range of discontinuation-related information, including type of discontinuation (permanent or temporary), motivation for switching, and reasons for nonadherent behavior. The reasons for discontinuation were ranked based on reporting frequency across the final set of studies. The ability to conduct quantitative comparisons using these data was limited, owing to differences in discontinuation reason descriptions and heterogeneity across study populations.

\section{Results \\ Systematic literature search}

The initial literature search yielded 1,384 citations. Following the level I screening, 452 publications and an additional eleven studies identified through the citation search were included for full text review. The full text screening identified 127 publications meeting all selection criteria (Figure 1). The final lists of publications are shown in Table S2 (original research studies) and Table S3 (expert opinion articles). Study-level specifics, methodology, and detailed persistence/discontinuation, and/or adherence information were extracted and analyzed for all 127 publications. Details of the number of studies conducted, stratified by age, medication class, and geographic location are summarized in Table 2.

\section{Persistence/discontinuation}

A total of 67 studies reported findings on persistence/ discontinuation: 52 were retrospective database analyses (based on health insurance claims, registries, or patient chart data) and 15 were patient or parent/caregiver surveys.

\section{Database studies}

Within the 52 retrospective database studies, three types of persistence measures were reported: discontinuation or continuation/persistence rate; treatment duration; and switching rate. Discontinuation of the index medication was generally defined as a gap, typically 30 days or more, in refill activity after the theoretical end date of the previous prescription.

Considerable heterogeneity existed across methodologies and reported outcomes in the persistence/discontinuation 


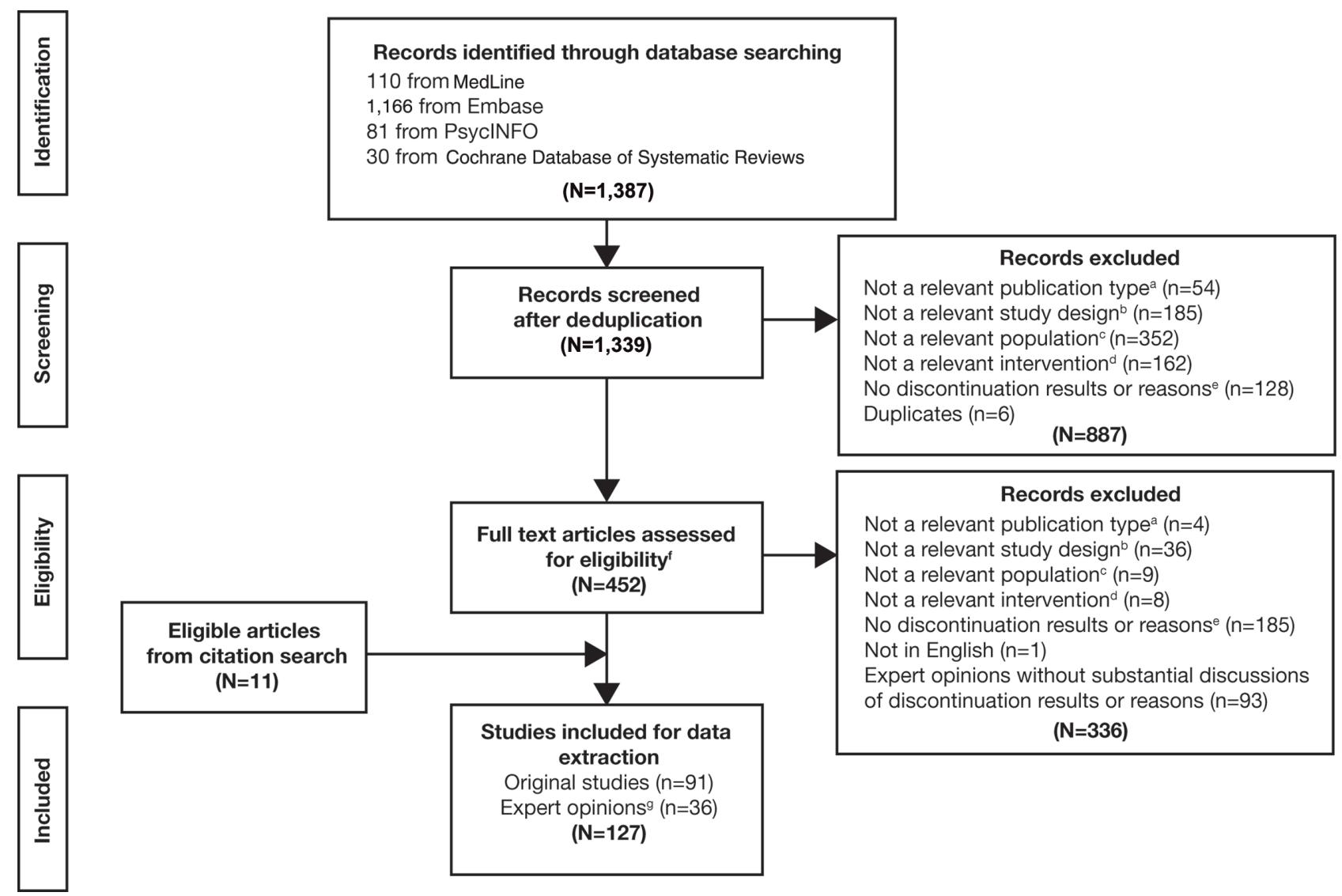

Figure I PRISMA diagram of the literature selection criteria.

Notes: ${ }^{a}$ Nonrelevant publication type: I) nonprimary publications of the real-world studies (eg, a publication that has less data than the primary publication to report the same outcomes); 2) conference abstracts or posters; 3) Congress proceedings; 4) books/chapters/addresses/bibliographies/biographies/lectures; 5) case reports; letters; or 6) treatment guidelines for countries other than: US, Canada, UK, Germany, France, Spain, Italy, Sweden, and the Netherlands. ${ }^{b}$ Nonrelevant study design: preclinical studies; clinical trials; prognostic studies; genetic studies; nonpopulation-based interview studies; economic studies; reviews/meta-analyses not of real-world studies. 'Nonrelevant population: nonhuman subjects; not ADHD patients; $<80 \%$ of the study population have ADHD as the primary disorder. ${ }^{d}$ Nonrelevant intervention: no drug treatment; drug treatment not of interest: stimulants (methylphenidate, amphetamine: amphetamine/dexamphetamine and lisdexamfetamine), nonstimulants (atomoxetine, guanfacine immediate/extended release, and clonidine immediate/extended release). eNonrelevant outcome: I) does not report discontinuation/continuation results; and 2) does not report reasons for ADHD drug discontinuation. 'FFor expert opinions (reviews, meta-analysis, editorials/commentaries, treatment guidelines), all the relevant citations for ADHD medication adherence or discontinuation were reviewed, and original papers were screened for inclusion. Reviews and meta-analyses were included for data extraction if they reported expert opinions that were not based on original studies. ${ }^{8}$ Expert opinions refer to reviews, meta-analysis, editorials/ commentaries, treatment guidelines.

Abbreviations: PRISMA, Preferred Reporting Items for Systematic Reviews and Meta-Analyses; ADHD, attention-deficit/hyperactivity disorder.

literature, with the most significant differences occurring in the definition of discontinuation, where gap length varied from 15 to 180 days, ${ }^{23-25}$ and study length varied from 60 days to 6 years. ${ }^{26,27}$ Given that persistence declines with time, reliable comparisons of discontinuation rate, treatment duration, or switching rate across studies with different study period lengths were not feasible.

\section{Discontinuation or continuation/persistence rate}

Thirty-seven studies reported discontinuation or continuation/ persistence rates, defined as the proportion of patients who discontinued their index medication or the proportion of patients who continued treatment as prescribed. Of these studies, eleven reported discontinuation rates among combined groups of children, adolescents, and adults, one study focused on adults only, ${ }^{28}$ and 25 studies focused on children and adolescents only. Three studies ${ }^{29-31}$ reported results separately for those patients who were 18 years and under and for those $>18$ years of age.

Substantial differences in target medication classes existed across the persistence/discontinuation studies. Six studies examined discontinuation rates among nonstimulant users (ATX; guanfacine immediate release [GIR]; GXR; or clonidine users), while 16 studies reported discontinuation rates for stimulants only. Fifteen studies reported rates for both stimulants and nonstimulants. Four studies $^{8,29,32,33}$ reported results separately for stimulants and nonstimulants. 
Table 2 Number of studies reporting results for subgroups

\begin{tabular}{|c|c|c|}
\hline & \multicolumn{2}{|l|}{ \# of studies } \\
\hline & Original study $(n=91)$ & Expert opinion $(n=36)$ \\
\hline \multicolumn{3}{|l|}{ Outcome } \\
\hline Persistence/discontinuation & 67 & NA \\
\hline Based on retrospective database & 52 & \\
\hline Based on patient and parent/caregiver surveys & 15 & \\
\hline Adherence & 26 & \\
\hline Based on retrospective database & 13 & \\
\hline Based on patient and parent/caregiver surveys & 10 & \\
\hline Based on physician surveys & 3 & \\
\hline Reasons for discontinuation/nonadherence & 41 & 36 \\
\hline \multicolumn{3}{|l|}{ Population } \\
\hline Children and adolescents & 62 & 24 \\
\hline Adults & 7 & I \\
\hline Combined age group of children, adolescents, adults ${ }^{a}$ & 22 & 11 \\
\hline \multicolumn{3}{|l|}{ Drug class } \\
\hline Stimulants & 56 & 18 \\
\hline Nonstimulants & 7 & 0 \\
\hline ADHD treatment including stimulants, nonstimulants ${ }^{\mathrm{b}}$ & 28 & 18 \\
\hline \multicolumn{3}{|l|}{ Geographic location } \\
\hline North America & 45 & 25 \\
\hline Europe & 33 & 7 \\
\hline Other parts of the world & 13 & 4 \\
\hline
\end{tabular}

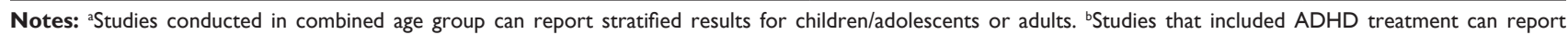
stratified results for stimulants or nonstimulants.

Abbreviations: NA, not applicable; ADHD, attention-deficit/hyperactivity disorder.

ADHD treatment discontinuation rates were reported in ten studies with a follow-up period of 12 months. Discontinuation rates for stimulants ranged from 19.1\% for LA stimulant users of all ages ${ }^{29}$ to $99 \%$ for SA MPH pediatric (6-12 years old) users. ${ }^{34}$ Discontinuation rates for nonstimulants, reported from two studies on the use of ATX, ranged from $26.0 \%$ for 6-17 year old Italian patients $^{33}$ to $38.3 \%$ for $2.5-90$ year old Canadians (in Quebec). ${ }^{29}$

\section{Treatment duration}

Thirteen studies reported treatment duration as the time during which patients remained on initial ADHD therapy until they discontinued. Of these, five studies ${ }^{35-39}$ (Table 3) employed the same definition of treatment duration - the number of days that a patient remained on his or her initial therapy during a 12-month follow-up period - and termination, which was defined as a gap of at least 30 days in prescription-filling activity. Of these studies, only four were used to create a pooled estimate (Table 4), because two studies $^{38,39}$ were kin studies. As Christensen et al ${ }^{38}$ reported additional results for AMPH, this study was chosen to be used for the analysis of treatment duration. Pooling of persistence estimates was only feasible for the children and adolescents population. Persistence ranged from 93.0 days (for SA stimulants) to 166.5 days (for AMPH). Only one study ${ }^{38}$ examined treatment duration among adults, reporting a range from 182.9 days (for MPH) to 252.7 days (for AMPH). The range of treatment duration reported for the overall age group was from 154.3 days (for nonstimulant ATX) to 254.2 days (for stimulants).

\section{Switching}

Switching to another medication was reported in 19 studies as either the rate of switching or the time to medication switch. Of these, six studies ${ }^{23,38-42}$ used a follow-up length of 12 months; the rate of switching in these studies ranged from $3.7 \%$ for patients $<18$ years old (switching from stimulants to nonstimulants) ${ }^{38}$ to $59 \%$ for children aged 6-12 years (switching from SA MPH to an unspecified ADHD medication) ${ }^{23}$

\section{Patient and parent/caregiver surveys}

Fifteen studies used patient or parent/caregiver interviews and surveys to assess persistence on ADHD medication. Of these, one study ${ }^{43}$ examined stimulant use among adults, while the remainder focused on ADHD pharmacotherapy among children and adolescents.

Discontinuation or continuation/persistence rates were reported in 13 of the studies. Among children and adolescents, 


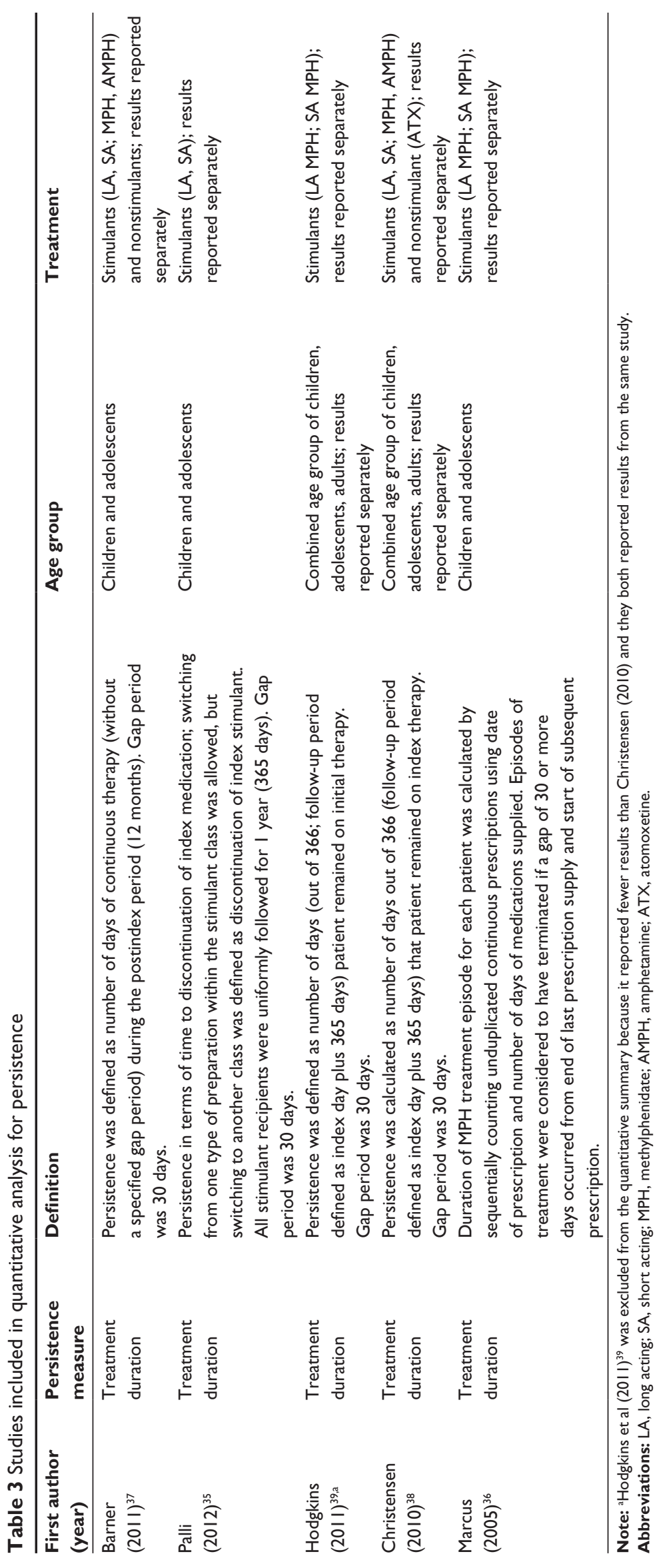




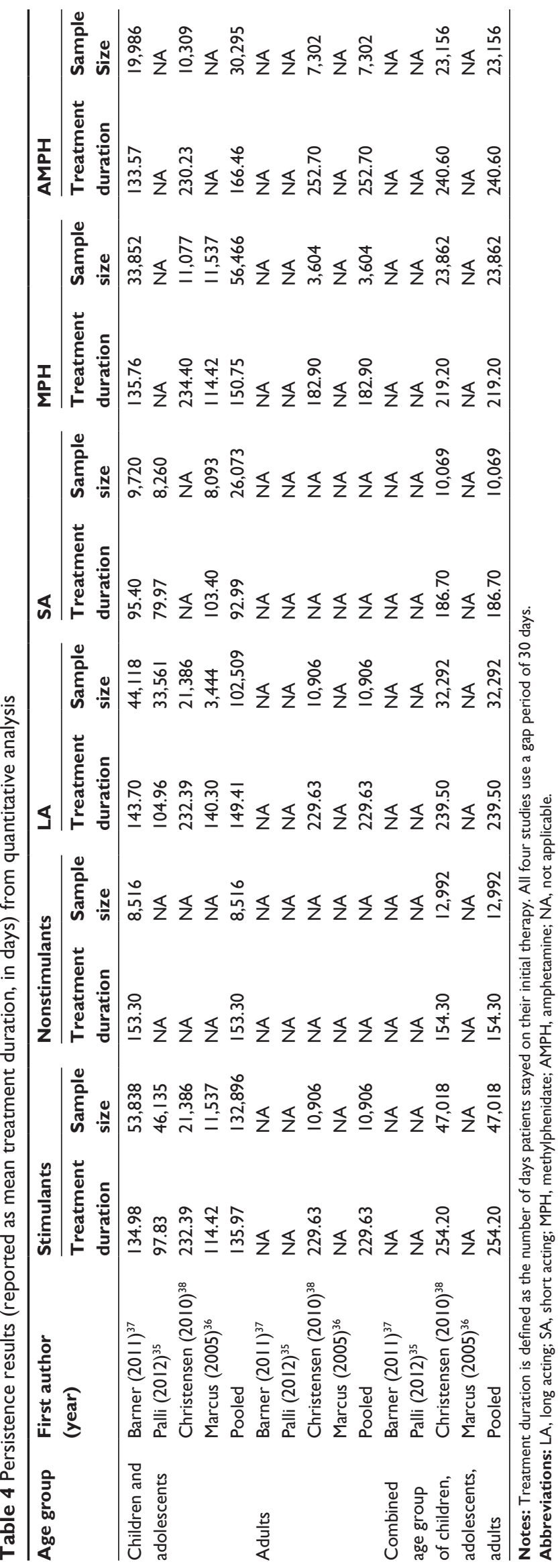

discontinuation rates ranged from $11.1 \%$ for $8-18$ year old patients, who stopped stimulant use following an average treatment duration of 3.3 years, ${ }^{44}$ to $96.4 \%$ for $4-17$ year old Puerto Ricans taking stimulants, and who were observed over a 1-year period. ${ }^{45}$ Treatment duration was reported in three survey-based studies ${ }^{46-48}$ and ranged from 79 days to 2.5 years; however, each study had a different follow-up length. Treatment switching was reported in one parent survey of Taiwanese children; the study found that $57 \%$ of patients classified as poor adherents switched from SA to $\mathrm{LA} \mathrm{MPH}^{49}$

\section{Adherence}

A total of 26 studies reported adherence results, of which 13 were retrospective database analyses, ten were patient or parent/caregiver surveys, and three were physician surveys.

\section{Database studies}

Twelve database studies used health insurance claims data from North American sources; only one study was conducted outside this region..$^{32}$ Overall, six studies examined adherence in combined populations of children, adolescents, and adults, ${ }^{29,30,38,39,42,50}$ while the remaining seven focused on adherence among children and adolescents only. Seven studies presented adherence results for both stimulants and nonstimulants, with each reported separately. Five studies assessed adherence to stimulant medications only (AMPH or MPH), ${ }^{24,30,50-52}$ and one study examined adherence to nonstimulants only (ie, GIR and GXR). ${ }^{53}$

All studies evaluated adherence as the number of days of medication supplied during a prespecified period. Ten studies defined adherence based on medication possession ratios (MPRs: the ratio of the number of days with medication supply to the total number of days in a defined period), while three studies employed days in possession ratio (DPR), ${ }^{30}$ annualized prescribed days,${ }^{54}$ and proportion of days covered (PDC). ${ }^{42}$ MPR was reported as a continuous measure of adherence in six studies and as a categorical variable (adherence defined by a given threshold value) in six studies. Of the latter, four studies defined being adherent as having an MPR of $>0.8,29,37,39,50$ while two employed an adherence threshold of 0.7..$^{51,52}$

Similar to the persistence/discontinuation studies, the length of study period varied across the 13 database studies, ranging from 3 months to $>2$ years. The most commonly used study period was 12 months (six studies),,$^{32,37-39,42,54}$ followed by 6 months (three studies) ${ }^{24,30,53}$ (Table 5). As patients' 


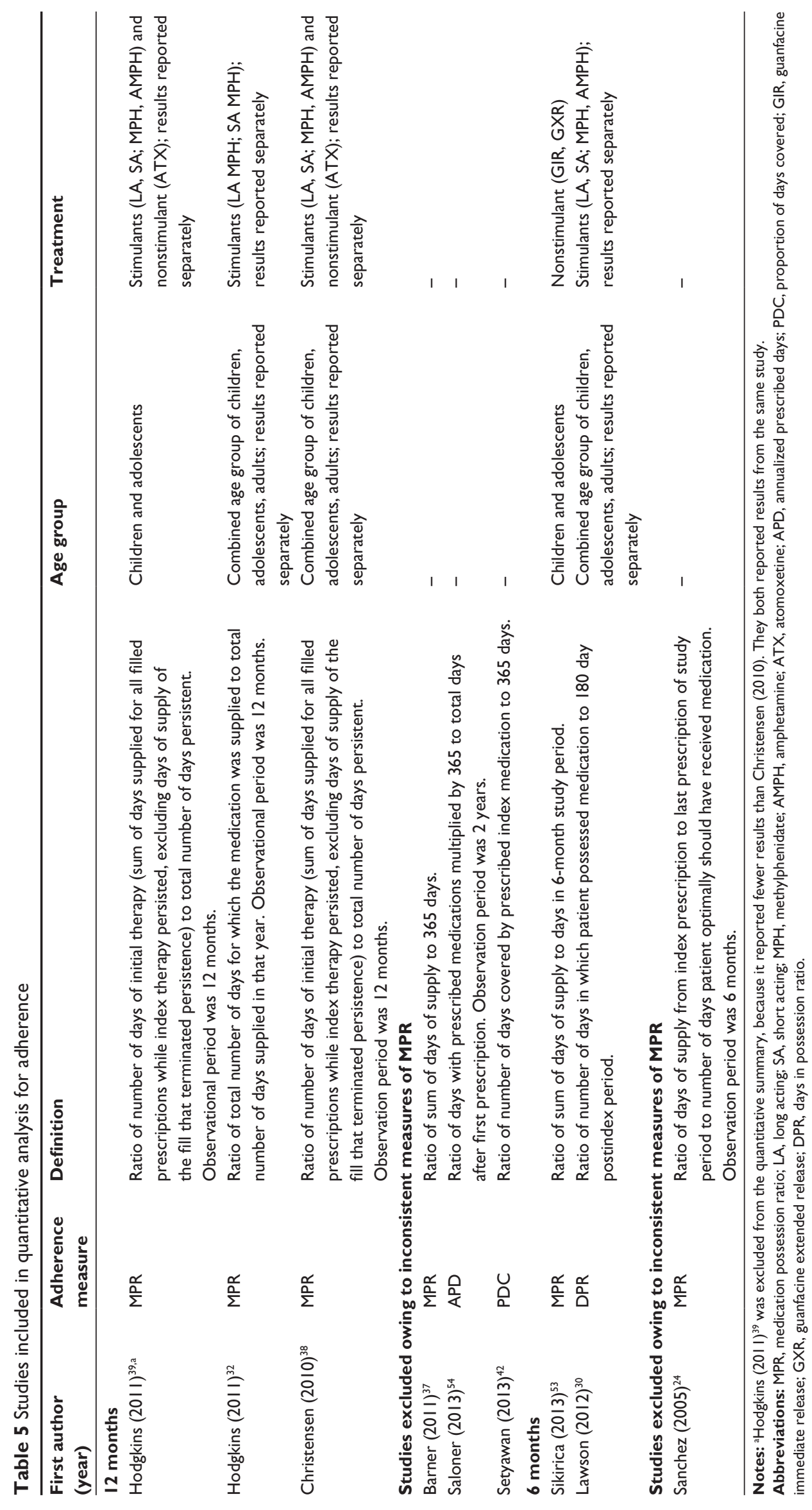


adherence levels may change over longer study periods, results were interpreted in the context of their observation length.

A quantitative pooling of MPR results was conducted in which comparable study measures were determined for each of the following groups - children and adolescents, adults, and the combined age group (Table 6). Among the six studies measuring adherence during a 12-month period, only two unique studies used the same adherence definition, calculating MPR as the ratio of supply days to the total number of persistent days during the follow-up period..$^{32,38,39}$ For the three studies using a 6-month period to measure adherence, ${ }^{24,30,53}$ only two studies used the same MPR definition ${ }^{30,53}$ - the ratio of supply days to a fixed postindex period of 180 days (Table 5). No pooled results could be estimated using these two studies, however, owing to the lack of a common treatment arm (each study examined a different medication class) (Table 6).

\section{Children and adolescents}

A total of 12 studies reported adherence results for patients aged $\leq 18$ years. For the eight studies in this group using MPR, PDC, or DPR, adherence ranged from 0.28 for treatment-experienced patients receiving SA MPH for 12 months to 0.76 for patients receiving LA MPH for 6 months. ${ }^{24,42}$ For studies using an MPR cut-off of 0.8 , the rate of adherence ranged from $9.8 \%$ (for patients using SA stimulants for 12 months) to $64 \%$ (for patients receiving stimulants and/or nonstimulants for 12 months). ${ }^{32,37}$

From the studies using a 12-month period, the pooled MPR for children and adolescents ranged from 0.56 for LA stimulants and AMPH to 0.67 for a nonstimulant (ATX). For the studies using a 6-month period, the pooled MPR ranged from 0.40 for SA stimulants to 0.61 for nonstimulants (GXR and GIR) (Table 6). Similar to the persistence analysis, the quantitative analysis for adherence was limited by the small number of studies sharing the same follow-up period and measure definitions.

\section{Adults}

Five studies reported adherence results for adults separately, using MPR, PDC, or DPR. ${ }^{29,30,38,39,42}$ Among the four studies that presented continuous measures of adherence, ${ }^{30,38,39,42}$ adherence ranged from 0.30 for treatment-experienced patients receiving SA MPH for 12 months $^{42}$ to 0.62 for patients receiving LA AMPH for 12 months. ${ }^{38}$ Pooling MPR results across adult ADHD studies was not feasible due to a lack of comparability of MPR definitions and study period lengths (Table 6).

\section{Patient and parent/caregiver surveys}

A total of ten studies conducted surveys and/or interviews to elicit assessments on medication adherence from patients with ADHD and their parents/caregivers. Two studies assessed adherence among adult patients with $\mathrm{ADHD},{ }^{43,55}$ while the remaining eight focused on child and adolescent populations. Compared with database studies on adherence, patient and parent/caregiver surveys were conducted over a wider geographic area: two in the US, ${ }^{56,57}$ three in Taiwan; ${ }^{49,58,59}$ and the remaining five in Norway, ${ }^{43}$ India,${ }^{60}$ Spain,,${ }^{55}$ Canada,,${ }^{61}$ a nd Saudi Arabia. ${ }^{62}$ Two studies reported combined adherence on both stimulants and nonstimulants, ${ }^{60,62}$ while the remainder looked only at stimulants. While all ten studies yielded similar adherence trends, multiple differences existed in study design and execution, limiting cross-comparison of results.

Of the ten survey studies, three compared adherence between LA and SA stimulants. ${ }^{43,49,55}$ Among these three studies, LA stimulants were found to have better adherence (ranging between $74.3 \%$ and $97.1 \%)^{49,55}$ than SA stimulants (ranging between $42.9 \%$ and $60.0 \%$ ). ${ }^{43,49}$ Definitions of adherence varied widely across these studies.

\section{Physician surveys}

Three studies used physician-estimated measures for adherence and treating physicians were asked to rate patient adherence on a questionnaire. Definitions of adherence varied widely across all three studies (eg, physicians' belief on whether patients were consistently compliant; ${ }^{63}$ identification of patients who were $>80 \%$ adherent to treatment during weekdays and $>50 \%$ adherent during weekends and holidays $;{ }^{64}$ or application of a 6-point scale to rate adherence $\left.{ }^{65}\right)$. Thus, adherence rates ranged between 57.1\% (African-American youths in the US rated as consistently compliant to stimulants over 2 years) ${ }^{63}$ and $71.4 \%$ (for 6-17 year old western European patients with ADHD evaluated for a minimum of 2 years postdiagnosis). ${ }^{64}$ As with prior adherence assessments, this analysis was limited by the heterogeneity of methodologies across studies and by small sample sizes.

\section{Reasons for treatment discontinuation}

The literature search identified 41 original real-world studies (Table S2) and 36 expert opinion articles (Table S3) reporting reasons for treatment discontinuation. Among the 41 original studies, $30(73 \%)$ reported reasons for discontinuation, seven $(17 \%)$ reported reasons for nonadherence, and seven (17\%) 


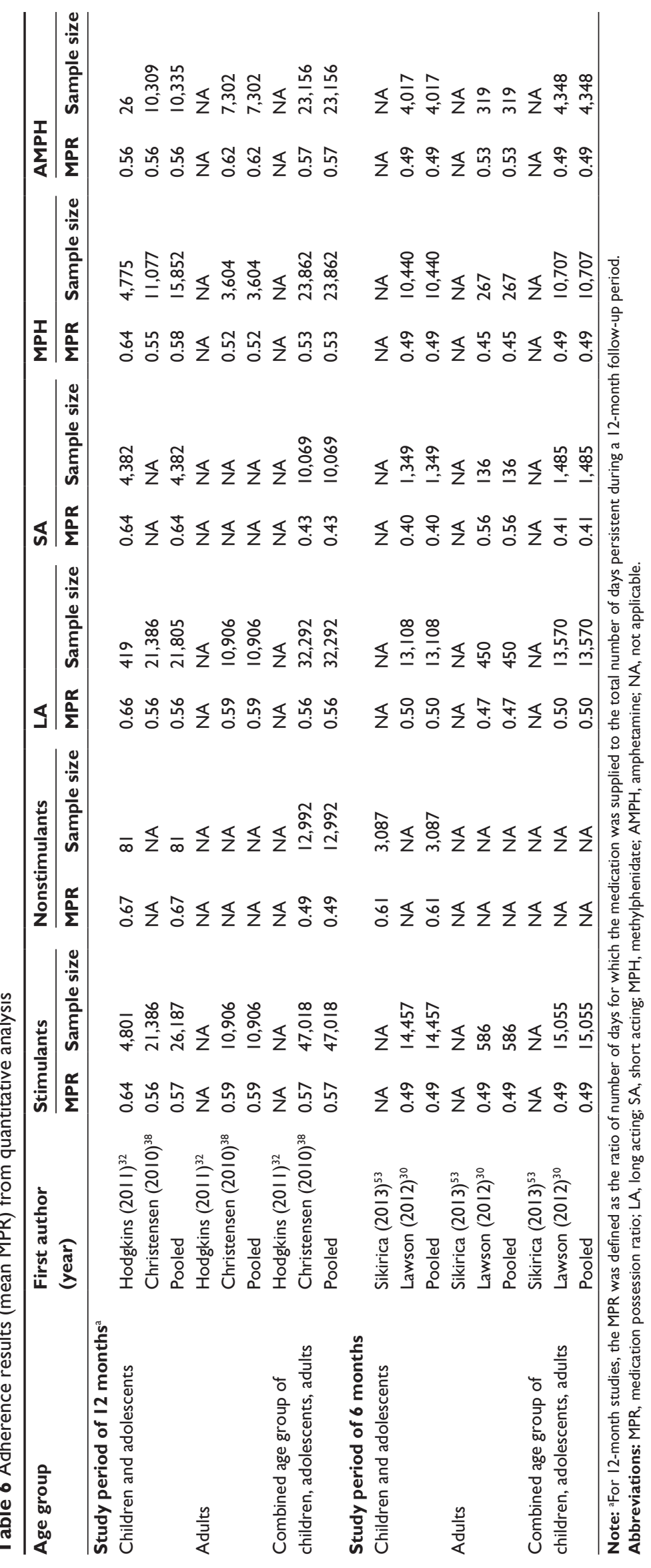


reported reasons for switching. Among the 36 expert opinion articles, $19(53 \%)$ reported reasons for discontinuation, while $24(67 \%)$ reported reasons for nonadherence, along with strategies to improve adherence. The following analysis of the reasons for discontinuation encompassed a broad range, including the type of discontinuation (permanent discontinuation of a medication or temporary discontinuation, such as a drug holiday), motivation for switching, and reasons for nonadherent behavior.

\section{Reasons for discontinuation from original research studies}

The most common reasons for discontinuing ADHD medications were adverse effects (reported in 30 out of 41 studies) and ineffective symptom control/suboptimal response (in 27 out of 41 studies) (Table 7). The studies were classified by age group and then analyzed by medication class, geographic region, and perspective for each age group.

\section{Children and adolescents}

Thirty-one (76\%) studies focused on reasons for discontinuing treatment among children and adolescents. The two most frequently reported discontinuation reasons for children and adolescents were adverse effects and treatment ineffectiveness/ suboptimal response (each reported in 21 out of 31 studies). Children and adolescents also frequently discontinued treatment due to poor adherence, parent/caregiver's decision to discontinue, and feeling that treatment was not needed due to symptom relief. Other reported reasons included patient attitude/dislike of medication, inconvenience of dosing, and the social stigma associated with ADHD and psychiatric medication, all of which are relevant in a school environment and might potentially explain children and adolescents' difficulty remaining on the medication.

Discontinuation reasons for children and adolescents treated with stimulants were extracted from 18 studies. The frequently cited reasons were: adverse effects; treatment ineffectiveness/suboptimal response; and poor adherence (each reported in more than five out of 18 studies). Other factors - such as symptom control, parent/caregiver's decision to discontinue, dislike of medication, and dosing inconvenience - were reported less frequently. Discontinuation reasons for children and adolescents treated with nonstimulants were detailed in only four studies. ${ }^{66-69}$ All four of these studies cited treatment ineffectiveness/suboptimal response, three cited adverse effects, and one cited poor adherence to treatment as reasons for discontinuation. For both medication classes, patient attitude was also a reason for discontinuation, although it was not frequently reported. For children and adolescents living in North America (ten studies), the primary reason for discontinuation was experiencing adverse effects (reported in seven out of ten studies), followed by treatment ineffectiveness/suboptimal response, dislike of medication, symptom relief, and the parent/caregiver's decision to discontinue (each reported in more than two out of ten studies). In Europe (15 studies), treatment ineffectiveness/suboptimal response was the main reason for discontinuation (reported in 14 out of 15 studies), followed by adverse effects, poor adherence, symptom control, and dosing inconvenience. Among the studies reporting discontinuation reasons from both the patient's and the parent/caregiver's perspective (14 studies), the top three discontinuation reasons were adverse effects, treatment ineffectiveness/suboptimal response, and parent/caregiver's decision to discontinue (each reported in more than four out of 14 studies). Studies reporting discontinuation reasons from the physician's perspective (14 studies) recounted the same top two reasons, and added poor patient adherence as the third most common reason.

Five of the 41 discontinuation studies (12\%) reported discontinuation reasons for children, adolescents, and young adults who were $<23$ years old. The overall results for this age group were similar to the patterns observed in children and adolescents, but one study reported lack of information about ADHD as the reason for discontinuation. All five studies focused on stimulants as a class or on MPH only. Owing to the small number of studies, information on other subgroups based on geographic region and perspective was sparse.

\section{Adults}

Only five (12\%) discontinuation studies covered treatment discontinuation reasons in adults. Of these studies, four focused on stimulants. ${ }^{28,36,43,70}$ The most common reasons for discontinuation were adverse effects and treatment ineffectiveness/suboptimal response (reported in three out of four studies). Other reported reasons included: achievement of symptom relief; misuse of medication; and the patient's decision to discontinue medication. Due to the small number of studies, information on other subgroups based on geographic region and perspective were sparse.

\section{Reasons for discontinuation based on expert opinions}

The literature review identified 36 expert opinion articles on ADHD treatment discontinuation (Table S3). The five most frequently encountered reasons for discontinuation were: adverse effects; dosing inconvenience; social stigma 


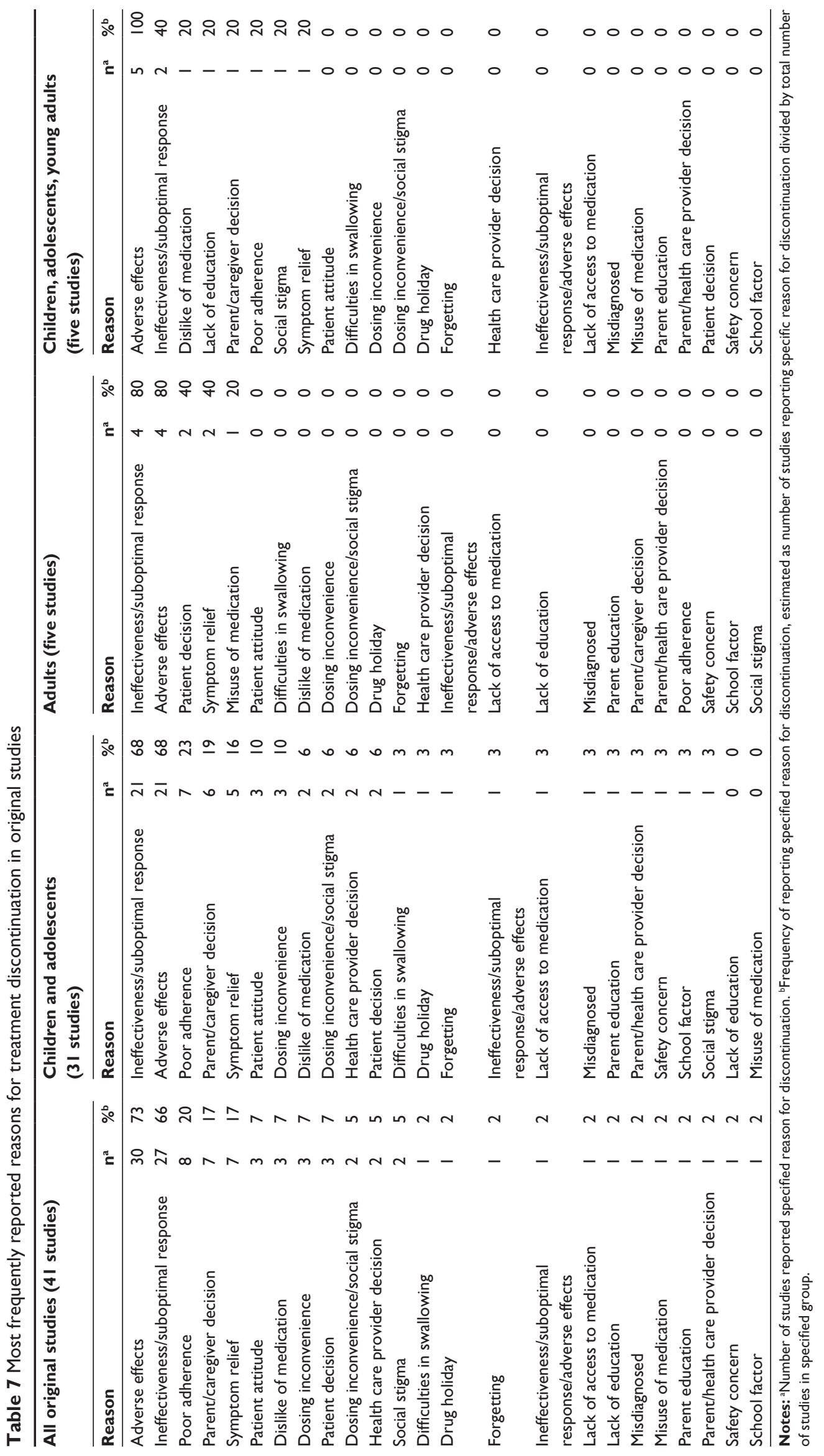


associated with ADHD and psychiatric medication; patient attitude; and treatment ineffectiveness/suboptimal response (Table 8).

When discontinuation reasons were analyzed by age group, children and adolescents (67\% of expert opinion studies) were shown to have similar reasons as those for the overall population analysis - adverse effects, dosing inconvenience, patient attitude, social stigma, and patient-physician communication. Commonly cited reasons for discontinuation of stimulant use by children and adolescents (12 studies) included: adverse effects, patient attitude, dosing inconvenience, social stigma, and patient-physician communication (each reported in more than three out of 12 studies). Other reasons included: difficulties in swallowing, disorder-related factors, inadequate monitoring, and treatment ineffectiveness/suboptimal response. No study reported discontinuation reasons for nonstimulants. The top five discontinuation reasons cited by experts in North America (17 studies) were: adverse effects, dosing inconvenience, patient attitude, social stigma, and patient-physician communication. Experts in Europe (five studies) ${ }^{71-75}$ provided similar reasons, with communication being replaced by inadequate monitoring.

In the only study from North America providing data on adult patients with ADHD (3\%), ${ }^{76}$ adverse effects, social stigma, and dosing inconvenience were listed as the reasons for discontinuation.

In the combined age group (30\% of expert opinion studies), six studies focused on stimulant discontinuation, ${ }^{65,77-81}$ and adverse effects were cited as a discontinuation reason in five of them. ${ }^{77-81}$ Other reasons given by experts for discontinuing stimulants included: treatment ineffectiveness/suboptimal response; difficulties in swallowing; dosing inconvenience; forgetfulness; and social stigma. No study provided discontinuation reasons for nonstimulants. Adverse effects and treatment ineffectiveness/suboptimal response were consistently referred to as the main reasons for discontinuation in the combined age group of children, adolescents, and adults by experts in North America (seven studies) and Europe (two studies) ${ }^{65,77}$ Experts from North America also cited: dosing inconvenience; forgetfulness; patient attitude, difficulties in swallowing, and social stigma as reasons for discontinuation. No additional reasons were provided by experts in Europe.

\section{Discussion}

This literature review examined persistence and adherence to pharmacologic treatment for ADHD and summarized reasons for treatment discontinuation. Where feasible, the analyses were also stratified across subgroups of patients by age group, geographic location, and medication class. Overall, findings from this study indicate that persistence and adherence to ADHD treatment were generally low and that tolerability was cited as an important reason for treatment discontinuation.

In our review of persistence studies, we observed that there was significant heterogeneity in measures of persistence in studies using patient/caregiver and physician surveys. The issue also affected retrospective database analyses, although to a lesser extent. Most of these studies measured persistence as time to a predefined prescription gap. However, variation in gap lengths and follow-up periods still exists. Rates of treatment persistence varied (between $0.1 \%$ and $89.9 \%$ ), depending on definitions across studies. Despite the variations, higher persistence was observed in patients using LA than SA stimulants.

Definitions of adherence were largely based on the number of days of medication supply. For all three types of studies examined - database studies, patient and parent/caregiver surveys, and physician surveys - adherence measure definitions and follow-up periods varied widely. Most studies reported rates of $<80 \%$ (or a mean MPR of $<0.8$ ), ${ }^{82}$ indicating a low treatment adherence for the ADHD population. From a societal perspective, it is often important to compare adherence across chronic diseases to help payers and policymakers understand how the adherence and its potential impact in one condition is relative to other similar conditions of interest. In general, adherence to ADHD medication was comparable with estimates reported for other psychiatric (schizophrenia, bipolar disorder $)^{83-85}$ and nonpsychiatric chronic disorders (hyperlipidemia, diabetes, hypertension, etc) ${ }^{82,86,87}$ with low adherence. There was no clear evidence that any subgroups (by age or medication class) experienced higher adherence than the others, but, in general, children and adolescents seemed to display higher adherence to nonstimulant than to stimulant medications. Adult adherence rates to various stimulant subcategories, ${ }^{30,38}$ as measured by MPR, suggest that patients on AMPH may have had higher adherence than those taking MPH; however, more comparable studies are needed to validate these results. The adherence estimates were not influenced by the length of the observation periods (eg, 6 months or 12 months).

This systematic literature review identified numerous reasons for discontinuation of ADHD medication. The most commonly cited reason for discontinuation in original research studies and expert opinion reviews was experiencing some adverse effects from the ADHD medication, regardless 


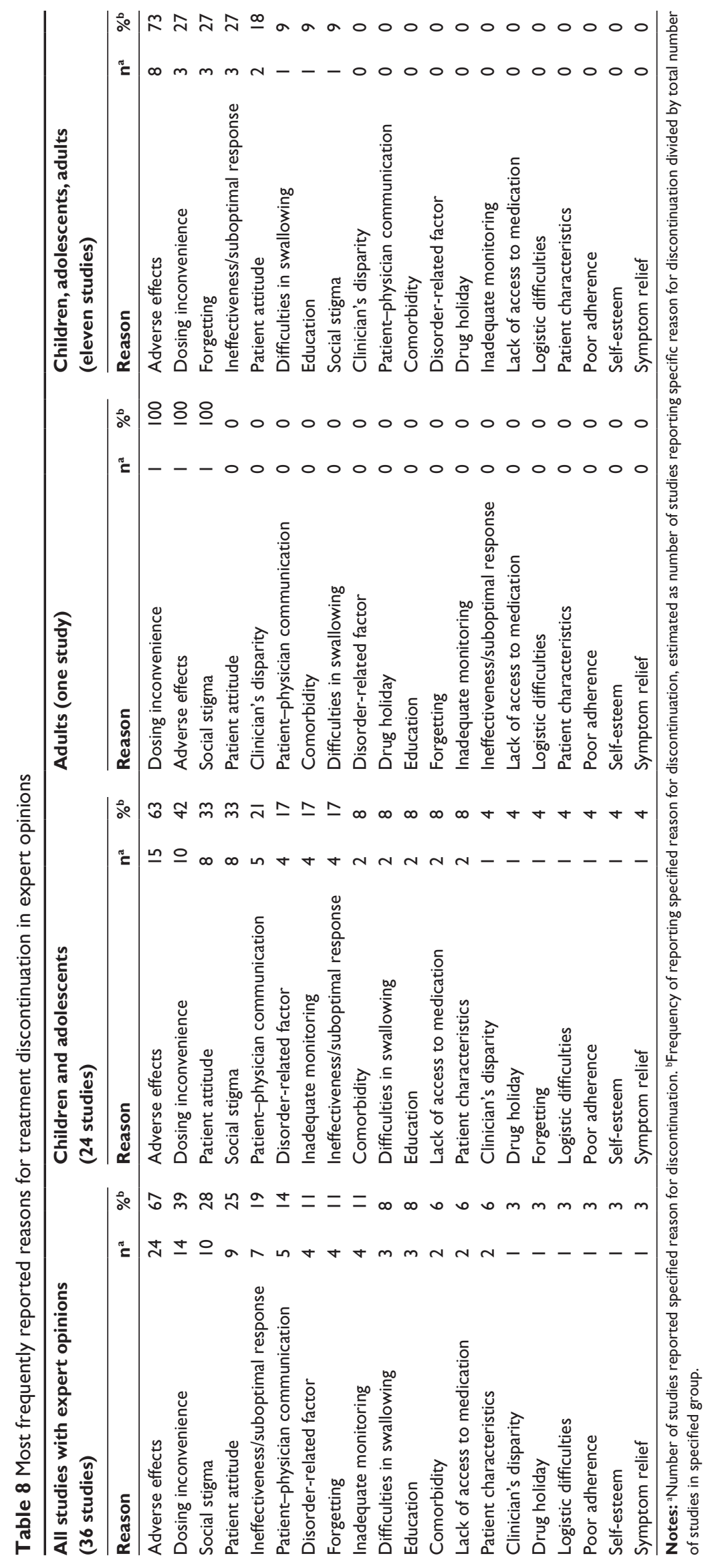


of age group, medication class, region, prior treatment status, and reporting perspective. Other reasons for discontinuation were generally similar across these two study types, although some differences were worth noting. Ineffectiveness/ suboptimal response was one of the most commonly reported reasons in the original studies, but it was reported less frequently in the expert opinion reviews (although it was still within the top five discontinuation explanations). Similarly, poor adherence was a commonly cited reason in the original studies but not in expert opinion reviews. In contrast, dosing inconvenience and social stigma were among the top five reasons in the expert opinion articles, but they were rarely reported in the original studies. Among adults, symptom relief, concerns over drug misuse, and desire to terminate treatment were frequent motivators. Among children and adolescents, discontinuation often occurred due to symptom relief, but also as a result of poor adherence or the parent/ caregiver's decision to discontinue.

This study observed a number of limitations in the existing body of evidence. First, due to the heterogeneity of study designs and methodology, the scope of a quantitative synthesis of persistence and adherence was limited. In the final quantitative analysis, the selection of eligible articles was narrowed down to a small list of directly comparable studies, which limited the generalizability of our conclusions. Second, the majority of original studies discussed reasons for discontinuation without reporting the proportion of patients affected by each reason; therefore, the rank of discontinuation reasons was based on frequencies of being reported in published studies. It was unclear whether most patients discontinued treatment due to the most frequently reported reasons in the literature. Third, reporting bias may exist as this study did not assess scientific quality of the included studies. Another limitation is related to the adverse effects that were reported to be the main reason for discontinuation across studies. The majority of studies did not provide details on the specific adverse effects that led to discontinuation. Hence, it was not clear if a particular side effect was responsible for a patient's unwillingness to continue treatment or if generally experiencing some unexpected or unpleasant side effect was sufficient to prompt treatment discontinuation.

Among the 91 original observational studies, only eleven studies reported adherence or discontinuation results for the adult ADHD population and, of these, only five original studies provided information on the underlying reasons for treatment discontinuation. Reasons for discontinuation for adults were provided in only one expert opinion article. This limited information on adherence and persistence in adults is one of the key findings and a call for action for further research to understand the adherence and persistence in the adult population.

Another important aspect of ADHD treatment is drug holidays (scheduled temporary suspensions of pharmacologic treatment). In this analysis, drug holidays were not always considered in studies of children and adolescents with ADHD. Stimulant-treated minors are often advised to take drug holidays during their school holidays or, sometimes, even weekends. Thus, observational database studies using persistence and adherence measures based on commonly used treatment gaps of 30 days may not have taken drug holidays into consideration and may have overestimated the rate of discontinuation - a type of attribution bias. Similarly, database studies measuring adherence as MPRs considered drug holidays as nonadherent days and, therefore, the adherence was underestimated in these studies.

Treatment adjustment is a common phenomenon with ADHD medication, and it should be taken into account when studying adherence and persistence measures. For example, the lower adherence and persistence with SA versus LA stimulants observed in the study could be attributed to a dose titration process. Patients initiating ADHD treatment are often started with low doses and then they titrate to an optimal dosage over time, to maximize medication effectiveness and minimize adverse effects. ${ }^{88,89}$ SA stimulants may be used for the first titration ${ }^{90}$ and, then, if the duration of effect of the optimized dosage is not adequate, patients are typically switched to LA formulations.

Over the past few decades, as ADHD knowledge has advanced, the use of alternative treatment modalities, such as the use of nonstimulants as adjunctive therapies to the core stimulant regimen for patients with suboptimal response to stimulant monotherapy, has increased. As ADHD care has evolved, so too should research into the adherence/ persistence of these alternative treatment approaches. ${ }^{91}$ Two nonstimulants have been approved in the US and Canada for adjunctive use. ${ }^{92,93}$ However, no observational study was identified in this systematic review evaluating persistence/ discontinuation and adherence of nonstimulants as adjunctive therapies; these newer treatment modalities may have different usage and outcome patterns compared with ADHD monotherapy.

Finally, differences in treatment settings (specialist versus generalist care) could not be considered in the scope of this review, as it was not reported consistently. Such differences could influence the reporting of specific discontinuation reasons across varying study types. For example, expert opinions may have been written by experienced child psychiatrists, who are more familiar with pharmacological treatment of 
ADHD - and in particular with stimulants. ${ }^{94}$ In addition, they may also have access to multiprofessional teams, facilitating patient management through multimodal treatment options, including continuous psychoeducation, cognitive behavioral therapy, parent training, etc. Thus, these practitioners may be less concerned about ineffectiveness/suboptimal response, as observed in our review. In contrast, physician survey studies could potentially include primary care physicians and pediatricians, who may be less familiar with medical treatment regimens for ADHD and thus may exhibit greater concerns regarding ineffectiveness/suboptimal response of the treatment.

These limitations highlight some gaps in the existing literature and provide possible directions for future research. Studies using comparable definitions and follow-up periods for different subgroups of patients with ADHD are needed to fill the current knowledge gap on the actual rates of adherence to pharmacologic treatment for ADHD. In particular, the current review confirms that treatment patterns in adult ADHD are poorly understood and that further studies are still required to shed light on how disease management approaches in this population will be different from that in children and adolescents. Similarly, systematic comparisons across other subgroups based on medication class (stimulants versus nonstimulants) and formulations (LA versus SA) should also be considered to inform what treatment strategies should be adopted to maintain persistence and adherence for these subgroups. In addition, with the increasing use of adjunctive therapies in the treatment of ADHD, disease management can also benefit from more real-world evidence on the treatment patterns of adjunctive therapies. Large observational studies in which patients are closely followed could provide more reliable estimates of treatment persistence and adherence. Future research that comprehensively collects reasons for discontinuation of ADHD treatment - adjusted for differences in treatment settings, age groups, and medication type - is warranted and will help patients and clinicians choose, monitor, and improve future ADHD treatment regimens.

\section{Conclusion}

In this systematic literature review and analysis, persistence and adherence to pharmacologic treatments for ADHD were generally inadequate. The highest persistence was generally observed for patients taking LA stimulants (compared with all other formulations) although further comparative studies are needed. The most common reasons for discontinuation extracted from original studies included adverse effects of ADHD medication, treatment ineffectiveness/suboptimal response, and poor patient adherence to treatment. According to expert opinions, the main reasons for discontinuing ADHD medication were adverse effects of medication, dosing inconvenience, and social stigma associated with ADHD and psychiatric disorders in general. The findings suggest that although efficacy, social factors, convenience, and patient attitude may influence treatment adherence and discontinuation, tolerability remains the most important component to consider when deciding on a treatment regimen. Based on these findings, clinicians may be able to help improve treatment adherence and persistence in this chronic disease by educating caregivers and patients on treatment goals, administering LA medications, and continuing to closely follow-up with patients to verify if medication is still effective and well-tolerated and to ensure medication is switched when there are tolerability issues or lack of symptom control.

\section{Acknowledgments}

The authors take full responsibility for the content of this paper, but thank Ana Bozas and Gourab De, employees of Analysis Group Inc., who contributed to the preparation of the manuscript, Caudex Medical (supported by Shire International $\mathrm{GmbH}$, Switzerland) for their editorial assistance and for the collation of comments from the authors and other named contributors, and Antonia Panayi of Shire International $\mathrm{GmbH}$ for helpful comments.

\section{Disclosure}

Research for this invited review was funded by the sponsor, Shire Development, LLC. Although the sponsor was involved in the design, collection, analysis, interpretation, and the information fact checking, the content of this manuscript, the ultimate interpretation, and the decision to submit it for publication were made by each of the authors independently. Vanja Sikirica and Kavita Gajria are employees of Shire and hold stock/stock options in Shire. Shire develops and markets medications to treat psychiatric conditions, including ADHD. Jipan Xie, Mei Lu, Yichen Zhong, and Paige Qin are employees of Analysis Group, Inc., a consultant for Shire. Peter Greven reports no financial conflicts of interest.

\section{References}

1. American Psychiatric Association. The Diagnostic and Statistical Manual of Mental Disorders. 5th edition. Arlington, VA: American Psychiatric Association; 2013.

2. Polanczyk G, de Lima MS, Horta BL, Biederman J, Rohde LA. The worldwide prevalence of ADHD: a systematic review and metaregression analysis. Am J Psychiatry. 2007;164(6):942-948.

3. Brown TE. ADHD Comorbidities: Handbook for ADHD Complications in Children and Adults. Washington, DC: American Psychiatric Press; 2009. 
4. Wu EQ, Hodgkins P, Ben-Hamadi R, et al. Cost effectiveness of pharmacotherapies for attention-deficit hyperactivity disorder: a systematic literature review. CNS Drugs. 2012;26(7):581-600.

5. Subcommittee on Attention-Deficit/Hyperactivity Disorder; Steering Committee on Quality Improvement and Management, Wolraich M, Brown L, Brown RT, et al. ADHD: clinical practice guideline for the diagnosis, evaluation, and treatment of attentiondeficit/hyperactivity disorder in children and adolescents. Pediatrics. 2011;128(5):1007-1022.

6. Ferrin M, Taylor E. Child and caregiver issues in the treatment of attention deficit-hyperactivity disorder: education, adherence and treatment choice. Future Neurol. 2011;6(3):399-413.

7. Zetterqvist $\mathrm{J}$, Asherson $\mathrm{P}$, Halldner L, Långström N, Larsson $\mathrm{H}$. Stimulant and non-stimulant attention deficit/hyperactivity disorder drug use: total population study of trends and discontinuation patterns 2006-2009. Acta Psychiatr Scand. 2013;128(1):70-77.

8. Garbe E, Mikolajczyk RT, Banaschewski T, et al. Drug treatment patterns of attention-deficit/hyperactivity disorder in children and adolescents in Germany: results from a large population-based cohort study. J Child Adolesc Psychopharmacol. 2012;22(6):452-458.

9. Hong J, Novick D, Treuer T, et al. Predictors and consequences of adherence to the treatment of pediatric patients with attention-deficit/ hyperactivity disorder in Central Europe and East Asia. Patient Prefer Adherence. 2013;7:987-995.

10. Adler LD, Nierenberg AA. Review of medication adherence in children and adults with ADHD. Postgrad Med. 2010;122(1):184-191.

11. Mannuzza S, Klein RG, Bessler A, Malloy P, LaPadula M. Adult outcome of hyperactive boys. Educational achievement, occupational rank, and psychiatric status. Arch Gen Psychiatry. 1993;50(7):565-576.

12. Shaw M, Hodgkins P, Caci H, et al. A systematic review and analysis of long-term outcomes in attention deficit hyperactivity disorder: effects of treatment and non-treatment. BMC Med. 2012;10:99.

13. Klein RG, Mannuzza S, Olazagasti MA, et al. Clinical and functional outcome of childhood attention-deficit/hyperactivity disorder 33 years later. Arch Gen Psychiatry. 2012;69(12):1295-1303.

14. Charach A, Fernandez R. Enhancing ADHD medication adherence: challenges and opportunities. Curr Psychiatry Rep. 2013;15(7):371.

15. Wong IC, Asherson P, Bilbow A, et al. Cessation of attention deficit hyperactivity disorder drugs in the young (CADDY) - a pharmacoepidemiological and qualitative study. Health Technol Assess. 2009;13(50):iii-iv, ix-xi, 1-120.

16. Ovid MedLine [database on the Internet]. Bethesda, MD: National Library of Medicine. Available from: http://site.ovid.com/products/ ovidguide/premdb.htm. Accessed January 11, 2014.

17. MEDLINE ${ }^{\circledR}$ [database on the Internet]. Bethesda, MD: National Library of Medicine. Available from: http://www.nlm.nih.gov/pubs/factsheets/ medline.html. Accessed October 21, 2013.

18. Embase [database on the Internet]. Philadelphia PA: Elsevier Inc. Available from: http://www.elsevier.com/online-tools/embase/about. Accessed January 11, 2014.

19. PsycINFO [database on the Internet]. Washington, DC: American Psychological Association. Available from: http://www.apa.org/pubs/ databases/psycinfo/index.aspx?utm_source=BenchmarkEmail\&utm_ campaign=0319-part01\&utm_medium=email. Accessed January 15 , 2014.

20. Cochrane Database of Systematic Reviews (CDSR) [database on the Internet]. London: The Cochrane Collaboration. Available from: http:// www.cochrane.org/editorial-and-publishing-policy-resource/cochranedatabase-systematic-reviews-cdsr. Accessed January 11, 2014.

21. Moher D, Liberati A, Tetzlaff J, Altman DG; PRISMA Group. Preferred reporting items for systematic reviews and meta-analyses: the PRISMA statement. PLoS Med. 2009;6(7):e1000097.

22. Greenhalgh T, Peacock R. Effectiveness and efficiency of search methods in systematic reviews of complex evidence: audit of primary sources. BMJ. 2005;331(7524):1064-1065.

23. Lage M, Hwang P. Effect of methylphenidate formulation for attention deficit hyperactivity disorder on patterns and outcomes of treatment. J Child Adolesc Psychopharmacol. 2004;14(4):575-581.
24. Sanchez RJ, Crismon ML, Barner JC, Bettinger T, Wilson JP. Assessment of adherence measures with different stimulants among children and adolescents. Pharmacotherapy. 2005;25(7): 909-917.

25. McCarthy S, Asherson P, Coghill D, et al. Attention-deficit hyperactivity disorder: treatment discontinuation in adolescents and young adults. Br J Psychiatry. 2009;194(3):273-277.

26. Johnston JA, Ye W, Van Brunt DL, Pohl G, Sumner CR. Decreased use of clonidine following treatment with atomoxetine in children with ADHD. J Clin Psychopharmacol. 2006;26(4):389-395.

27. Bokhari FAS, Heiland F, Levine P, Ray GT. Risk factors for discontinuing drug therapy among children with ADHD. Health Serv Outcomes Res Methodol. 2008;8(3):134-158.

28. Bejerot S, Rydén EM, Arlinde CM. Two-year outcome of treatment with central stimulant medication in adult attention-deficit/hyperactivity disorder: a prospective study. J Clin Psychiatry. 2010;71(12): $1590-1597$.

29. Lachaine J, Beauchemin C, Sasane R, Hodgkins PS. Treatment patterns, adherence, and persistence in ADHD: a Canadian perspective. Postgrad Med. 2012;124(3):139-148.

30. Lawson KA, Johnsrud M, Hodgkins P, Sasané R, Crismon ML. Utilization patterns of stimulants in ADHD in the Medicaid population: a retrospective analysis of data from the Texas Medicaid program. Clin Ther. 2012;34(4):944-956.e4

31. Pottegård A, Bjerregaard BK, Glintborg D, Kortegaard LS, Hallas J, Moreno SI. The use of medication against attention deficit/hyperactivity disorder in Denmark: a drug use study from a patient perspective. Eur J Clin Pharmacol. 2013;69(3):589-598.

32. Hodgkins P, Sasané R, Meijer WM. Pharmacologic treatment of attention-deficit/hyperactivity disorder in children: incidence, prevalence, and treatment patterns in the Netherlands. Clin Ther. 2011;33(2): 188-203.

33. Didoni A, Sequi M, Panei P, Bonati M; Lombardy ADHD Registry Group. One-year prospective follow-up of pharmacological treatment in children with attention-deficit/hyperactivity disorder. Eur J Clin Pharmacol. 2011;67(10):1061-1067.

34. Chen CY, Yeh HH, Chen KH, Chang IS, Wu EC, Lin KM. Differential effects of predictors on methylphenidate initiation and discontinuation among young people with newly diagnosed attention-deficit/ hyperactivity disorder. J Child Adolesc Psychopharmacol. 2011;21(3): 265-273.

35. Palli SR, Kamble PS, Chen H, Aparasu RR. Persistence of stimulants in children and adolescents with attention-deficit/hyperactivity disorder. J Child Adolesc Psychopharmacol. 2012;22(2):139-148.

36. Marcus SC, Wan GJ, Kemner JE, Olfson M. Continuity of methylphenidate treatment for attention-deficit/hyperactivity disorder. Arch Pediatr Adolesc Med. 2005;159(6):572-578.

37. Barner JC, Khoza S, Oladapo A. ADHD medication use, adherence, persistence and cost among Texas Medicaid children. Curr Med Res Opin. 2011;27 Suppl 2:13-22.

38. Christensen L, Sasané R, Hodgkins P, Harley C, Tetali S. Pharmacological treatment patterns among patients with attentiondeficit/hyperactivity disorder: retrospective claims-based analysis of a managed care population. Curr Med Res Opin. 2010;26(4): 977-989.

39. Hodgkins P, Sasané R, Christensen L, Harley C, Liu F. Treatment outcomes with methylphenidate formulations among patients with ADHD: retrospective claims analysis of a managed care population. Curr Med Res Opin. 2011;27 Suppl 2:53-62.

40. Goetz M, Yeh CB, Ondrejka I, et al. A 12-month prospective, observational study of treatment regimen and quality of life associated with ADHD in central and eastern europe and eastern Asia. J Atten Disord. 2012;16(1):44-59.

41. Sikirica V, Pliszka SR, Betts KA, et al. Comparative treatment patterns, resource utilization, and costs in stimulant-treated children with $\mathrm{ADHD}$ who require subsequent pharmacotherapy with atypical antipsychotics versus non-antipsychotics. J Manag Care Pharm. 2012;18(9):676-689. 
42. Setyawan J, Hodgkins P, Guérin A, et al. Comparing treatment adherence of lisdexamfetamine and other medications for the treatment of attention deficit/hyperactivity disorder: a retrospective analysis. $J \mathrm{Med}$ Econ. 2013;16(7):962-975.

43. Lensing MB, Zeiner P, Sandvik L, Opjordsmoen S. Four-year outcome in psychopharmacologically treated adults with attention-deficit/ hyperactivity disorder: a questionnaire survey. J Clin Psychiatry. 2013;74(1):e87-e93.

44. Bowen J, Fenton T, Rappaport L. Stimulant medication and attention deficit-hyperactivity disorder. The child's perspective. Am J Dis Child. 1991;145(3):291-295.

45. Bauermeister JJ, Canino G, Bravo M, et al. Stimulant and psychosocial treatment of ADHD in Latino/Hispanic children. J Am Acad Child Adolesc Psychiatry. 2003;42(7):851-855.

46. Ercan ES, Kose S, Kutlu A, Akyol O, Durak S, Aydin C. Treatment duration of children with attention deficit hyperactivity disorder is related to functioning and prognosis. Bulletin of Clinical Psychopharmacology. 2012;22(2):148-160.

47. dosReis S, Butz A, Lipkin PH, Anixt JS, Weiner CL, Chernoff R. Attitudes about stimulant medication for attention-deficit/hyperactivity disorder among African American families in an inner city community. J Behav Health Serv Res. 2006;33(4):423-430.

48. Niederkirchner K, Slawik L, Wermelskirchen D, Rettig K, Schäuble B. Transitioning to OROS ${ }^{\circledR}$ methylphenidate from atomoxetine is effective in children and adolescents with ADHD. Expert Rev Neurother. 2011;11(4):499-508.

49. Gau SS, Chen SJ, Chou WJ, et al. National survey of adherence, efficacy, and side effects of methylphenidate in children with attention-deficit hyperactivity disorder in Taiwan. J Clin Psychiatry. 2008;69(1):131-140.

50. Kemner JE, Lage MJ. Impact of methylphenidate formulation on treatment patterns and hospitalizations: a retrospective analysis. Ann Gen Psychiatry. 2006;5:5.

51. Marcus SC, Durkin M. Stimulant adherence and academic performance in urban youth with attention-deficit/hyperactivity disorder. $\mathrm{J} \mathrm{Am} \mathrm{Acad}$ Child Adolesc Psychiatry. 2011;50(5):480-489.

52. Marcus SC, Wan GJ, Zhang HF, Olfson M. Injury among stimulanttreated youth with ADHD. J Atten Disord. 2008;12(1):64-69.

53. Sikirica V, Xie J, He TL, et al. Immediate-release versus extendedrelease guanfacine for treatment of attention-deficit/hyperactivity disorder. Am J Pharm Benefits. 2013;5(4):e85-e94.

54. Saloner B, Fullerton C, McGuire T. The impact of long-acting medications on attention-deficit/hyperactivity disorder treatment disparities. J Child Adolesc Psychopharmacol. 2013;23(6):401-409.

55. Ramos-Quiroga JA, Bosch R, Castells X, et al. Effect of switching drug formulations from immediate-release to extended-release OROS methylphenidate: a chart review of Spanish adults with attention-deficit hyperactivity disorder. CNS Drugs. 2008;22(7):603-611.

56. Gimpel GA, Collett BR, Veeder MA, et al. Effects of stimulant medication on cognitive performance of children with ADHD. Clin Pediatr (Phila). 2005;44(5):405-411.

57. Coletti DJ, Pappadopulos E, Katsiotas NJ, Berest A, Jensen PS, Kafantaris V. Parent perspectives on the decision to initiate medication treatment of attention-deficit/hyperactivity disorder. J Child Adolesc Psychopharmacol. 2012;22(3):226-237.

58. Chou WJ, Chou MC, Tzang RF, et al. Better efficacy for the osmotic release oral system methylphenidate among poor adherents to immediaterelease methylphenidate in the three ADHD subtypes. Psychiatry Clin Neurosci. 2009;63(2):167-175.

59. Gau SS, Shen HY, Chou MC, Tang CS, Chiu YN, Gau CS. Determinants of adherence to methylphenidate and the impact of poor adherence on maternal and family measures. J Child Adolesc Psychopharmacol. 2006;16(3):286-297.

60. Sitholey P, Agarwal V, Chamoli S. A preliminary study of factors affecting adherence to medication in clinic children with attention-deficit/ hyperactivity disorder. Indian J Psychiatry. 2011;53(1):41-44.

61. Thiruchelvam D, Charach A, Schachar RJ. Moderators and mediators of long-term adherence to stimulant treatment in children with ADHD. J Am Acad Child Adolesc Psychiatry. 2001;40(8):922-928.
62. Ibrahim el SR. Rates of adherence to pharmacological treatment among children and adolescents with attention deficit hyperactivity disorder. Hum Psychopharmacol. 2002;17(5):225-231.

63. Hervey-Jumper H, Douyon K, Franco KN. Deficits in diagnosis, treatment and continuity of care in African-American children and adolescents with ADHD. J Natl Med Assoc. 2006;98(2):233-238.

64. Hodgkins P, Setyawan J, Mitra D, et al. Management of ADHD in children across Europe: patient demographics, physician characteristics and treatment patterns. Eur J Pediatr. 2013;172(7):895-906.

65. Rothenberger A, Becker A, Breuer D, Döpfner M. An observational study of once-daily modified-release methylphenidate in ADHD: quality of life, satisfaction with treatment and adherence. Eur Child Adolesc Psychiatry. 2011;20 Suppl 2:S257-S265.

66. Mazzone L, Reale L, Mannino V, Cocuzza M, Vitiello B. Lower IQ is associated with decreased clinical response to atomoxetine in children and adolescents with attention-deficit hyperactivity disorder. CNS Drugs. 2011;25(6):503-509.

67. Torres A, Whitney J, Rao S, Tilley C, Lobel R, Gonzalez-Heydrich J. Tolerability of atomoxetine for treatment of pediatric attention-deficit/ hyperactivity disorder in the context of epilepsy. Epilepsy Behav. 2011;20(1):95-102.

68. Scott NG, Ripperger-Suhler J, Rajab MH, Kjar D. Factors associated with atomoxetine efficacy for treatment of attention-deficit/hyperactivity disorder in children and adolescents. J Child Adolesc Psychopharmacol. 2010;20(3):197-203.

69. Banerjee S. Use of atomoxetine in children and adolescents with ADHD. Prog Neurol Psychiatry. 2009;13(2):18-20.

70. Darredeau C, Barrett SP, Jardin B, Pihl RO. Patterns and predictors of medication compliance, diversion, and misuse in adult prescribed methylphenidate users. Hum Psychopharmacol. 2007;22(8): 529-536.

71. Rothenberger A, Rothenberger LG. Updates on treatment of attentiondeficit/hyperactivity disorder: facts, comments, and ethical considerations. Curr Treat Options Neurol. 2012;14(6):594-607.

72. Ashton H, Gallagher P, Moore B. The adult psychiatrist's dilemma: psychostimulant use in attention deficit/hyperactivity disorder. $J$ Psychopharmacol. 2006;20(5):602-610.

73. Schlander M. Is NICE infallible? A qualitative study of its assessment of treatments for attention-deficit/hyperactivity disorder (ADHD). Curr Med Res Opin. 2008;24(2):515-535.

74. Buitelaar J, Medori R. Treating attention-deficit/hyperactivity disorder beyond symptom control alone in children and adolescents: a review of the potential benefits of long-acting stimulants. Eur Child Adolesc Psychiatry. 2010;19(4):325-340.

75. Graham J, Banaschewski T, Buitelaar J, et al; European Guidelines Group. European guidelines on managing adverse effects of medication for ADHD. Eur Child Adolesc Psychiatry. 2011;20(1):17-37.

76. Dodson WW. Pharmacotherapy of adult ADHD. J Clin Psychol. 2005; 61(5):589-606.

77. Rösler M, Casas M, Konofal E, Buitelaar J. Attention deficit hyperactivity disorder in adults. World J Biol Psychiatry. 2010;11(5): 684-698.

78. Graham L. Practice guidelines: AHA releases recommendations on cardiovascular monitoring and the use of ADHD medications in children with heart disease. Am Fam Physician. 2009;79(10):905-910.

79. Coury D. Dexmethylphenidate for attention deficit hyperactivity disorder. Expert Opin Pharmacother. 2009;10(16):2679-2685.

80. Greenhill LL, Pliszka S, Dulcan MK, et al; American Academy of Child and Adolescent Psychiatry. Practice parameter for the use of stimulant medications in the treatment of children, adolescents, and adults. $J \mathrm{Am}$ Acad Child Adolesc Psychiatry. 2002;41(2 Suppl):26S-49S.

81. Van Cleave J, Leslie LK. Approaching ADHD as a chronic condition: implications for long-term adherence. J Psychosoc Nurs Ment Health Serv. 2008;46(8):28-37.

82. Karve S, Cleves MA, Helm M, Hudson TJ, West DS, Martin BC. Good and poor adherence: optimal cut-point for adherence measures using administrative claims data. Curr Med Res Opin. 2009;25(9): 2303-2310. 
83. Cramer JA, Rosenheck R. Compliance with medication regimens for mental and physical disorders. Psychiatr Serv. 1998;49(2):196-201.

84. Chapman SC, Horne R. Medication nonadherence and psychiatry. Curr Opin Psychiatry. 2013;26(5):446-452.

85. Velligan DI, Weiden PJ, Sajatovic M, et al; Expert Consensus Panel on Adherence Problems in Serious and Persistent Mental Illness. The expert consensus guideline series: adherence problems in patients with serious and persistent mental illness. J Clin Psychiatry. 2009;70 Suppl 4: 1-46; quiz 47.

86. Dunbar-Jacob J, Mortimer-Stephens MK. Treatment adherence in chronic disease. J Clin Epidemiol. 2001;54 Suppl 1:S57-S60.

87. Yeaw J, Benner JS, Walt JG, Sian S, Smith DB. Comparing adherence and persistence across 6 chronic medication classes. J Manag Care Pharm. 2009;15(9):728-740.

88. Centers for Disease Control and Prevention [homepage on the Internet]. Attention-Deficit/Hyperactivity Disorder (ADHD). Atlanta, GA: Centers for Disease Control and Prevention; 2013 [update July 3, 2013]. Available from: http://www.cdc.gov/ncbddd/adhd/guidelines.html. Accessed March 19, 2014.

89. National Institute for Health and Clinical Excellence. Attention deficit hyperactivity disorder: Diagnosis and management of ADHD in children, young people and adults. Manchester, UK: NICE; 2013. Available from: http://www.nice.org.uk/nicemedia/live/12061/42059/42059.pdf. Accessed March 19, 2014.
90. Cascade E, Kalali AH, Weisler RH. Short-acting versus long-acting medications for the treatment of ADHD. Psychiatry (Edgmont). 2008; 5(8):24-27.

91. Sikirica V, Fridman M, Bruno A, Hodgkins P, Erder MH. Concomitant pharmacotherapy of psychotropic medications in EU children and adolescents with attention-deficit/hyperactivity disorder. Drugs $R D$. 2013; 13(4):271-280.

92. National Institute of Mental Health. Mental Health Medications. Bethesda, MD: National Institute of Mental Health; 2008. Available from: http:/www.nimh.nih.gov/health/publications/mental-healthmedications/index.shtml\#pub8. Accessed March 7, 2014.

93. Canadian Attention Deficit Hyperactivity Disorder Resource Alliance. Canadian ADHD Practice Guidelines. Toronto, ON: Canadian Attention Deficit Hyperactivity Disorder Resource Alliance; 2011. Available from: http://www.caddra.ca/pdfs/caddraGuidelines2011.pdf. Accessed March 7, 2014.

94. Faraone SV, Ansthel KM. Diagnosing and treating attention-deficit/ hyperactivity disorder in adults. World Psychiatry. 2008;7(3): $131-136$. 


\section{Supplementary materials}

Table SI A list of ADHD medications approved in North American and European countries

\begin{tabular}{|c|c|c|}
\hline Stimulants/nonstimulants & Medication class & $\begin{array}{l}\text { ADHD medications (Medication type, Formulation if available, } \\
\text { Manufacturer) }\end{array}$ \\
\hline \multirow[t]{6}{*}{ Nonstimulants } & Selective norepinephrine & Strattera ${ }^{\circledR}$ (ATX; Eli Lilly and Company) \\
\hline & reuptake inhibitor & Atomoxetine Teva (ATX; Teva) \\
\hline & Alpha-2 adrenergic agonist & Intuniv ${ }^{\circledast}$ (GXR; Shire) \\
\hline & & Guanfacine/Guanfasiini immediate release (GIR) \\
\hline & & Kapvay ${ }^{\circledR}$ (clonidine hydrochloride, extended release; Concordia Pharmaceuticals) \\
\hline & & Clonidine immediate release (CIR) \\
\hline \multirow[t]{46}{*}{ Stimulants } & Methylphenidate & Biphentin $^{\circledast}(\mathrm{MPH} ;$ Perdue Pharma) \\
\hline & & Concerta $^{\circledR}$ (MPH; Janssen Pharmaceuticals/ALZA Corporation) \\
\hline & & Daytrana $^{\circledR}$ (MPH; Noven Therapeutics) \\
\hline & & Elmifiten ${ }^{\circledR}$ (dexmethylphenidate; Alfred E Tiefenbacher Gmbh \& Co.) \\
\hline & & Equasym XL ${ }^{\circledast} /$ Equasym Retard ${ }^{\circledR} /$ Equasym Depot ${ }^{\circledR} /$ Quasym LP $^{\circledR}$ (MPH; Shire) \\
\hline & & Focalin ${ }^{\circledast}$ (dexmethylphenidate; Novartis) \\
\hline & & Focalin $X R^{\circledast}$ (dexmethylphenidate, extended release; Novartis) \\
\hline & & Metadate $^{\circledast}(\mathrm{MPH} ;$ UCB Pharma) \\
\hline & & Metadate $\mathrm{CD}^{\circledR}$ (MPH, extended release capsules; UCB Pharma) \\
\hline & & Metadate $\mathrm{ER}^{\circledR}$ (MPH, extended release tablets; UCB Pharma) \\
\hline & & Medicebran ${ }^{\circledast}(\mathrm{MPH}$; Laboratorios Farmacéuticos Rovi) \\
\hline & & Medikid $(\mathrm{MPH})$ \\
\hline & & Medikinet/Medikinet $\mathrm{CR}^{\circledR}(\mathrm{MPH}$; Medice) \\
\hline & & Medikinet $^{\circledR}$ XL (MPH; Medice) \\
\hline & & Medikinet Retard ${ }^{\circledR}(\mathrm{MPH}$; Medice $)$ \\
\hline & & Methylin ${ }^{\circledR}(\mathrm{MPH} ;$ Mallinckrodt/Shionogi) \\
\hline & & Methylin $\mathrm{ER}^{\circledast}$ (MPH, extended release; Mallinckrodt/Shionogi) \\
\hline & & Methylphenidat-IA pharma ${ }^{\circledR}(\mathrm{MPH} ;$ I A Pharma) \\
\hline & & Methylphenidat HEXAL ${ }^{\circledR}$ (MPH; Hexal) \\
\hline & & Methylphenidat-ratiopharm ${ }^{\circledR}(\mathrm{MPH}$; Ratiopharm) \\
\hline & & Methylpheni TAD ${ }^{\circledR}$ (MPH; TAD Pharma GmbH) \\
\hline & & Methylphenidat TB (MPH; Alfred E Tiefenbacher GmbH \& Co.) \\
\hline & & Methylfenidaat $\mathrm{HCl}(\mathrm{MPH}$, hydrochloride) \\
\hline & & Methylfenidaat $\mathrm{HCl}$ AET (MPH, hydrochloride; Alfred E Tiefenbacher GmbH \& Co.) \\
\hline & & Motiron ${ }^{\circledast}(\mathrm{MPH}$; Sandoz) \\
\hline & & Methylphenidate Rubio (MPH; Laboratorios Rubió) \\
\hline & & Omozin $^{\circledast}$ (MPH; Laboratorios Rubió) \\
\hline & & Ritalin/Ritaline ${ }^{\circledR}$ (MPH; Novartis) \\
\hline & & Ritalin LA ${ }^{\circledast}$ (MPH, long acting; Novartis) \\
\hline & & Ritalin $\mathrm{SR}^{\circledR}$ (MPH, sustained release; Novartis) \\
\hline & & Rubifen $^{\circledR}$ (MPH; Laboratorios Rubió) \\
\hline & & Tifinidat (MPH; Alfred E Tiefenbacher GmbH \& Co.) \\
\hline & & Quillivant $^{T M}$ (MPH; Pfizer) \\
\hline & & Quillivant $X^{T M}$ (MPH, extended release; Pfizer) \\
\hline & Amphetamine & Adderall $^{\circledast}$ (amphetamine/dextroamphetamine; Shire) \\
\hline & & Adderall $X R^{\circledR}$ (AMPH/dextroamphetamine, extended release; Shire) \\
\hline & & Dexedrine ${ }^{\circledR}$ SR (dextroamphetamine, sustained release; Amedra Pharmaceuticals) \\
\hline & & Dexedrine ${ }^{\circledR}$ spansules ${ }^{\circledR}$ (dextroamphetamine; Amedra Pharmaceuticals) \\
\hline & & Dextroamphetamine ER (dextroamphetamine, extended release) \\
\hline & & Desoxyn ${ }^{\circledR}$ (methamphetamine hydrochloride; Recordati Rare Diseases, INC.) \\
\hline & & Dexedrine ${ }^{\circledast}$ (dextroamphetamine; Amedra Pharmaceuticals LLC) \\
\hline & & Dextrostat $^{\circledR}$ (dextroamphetamine; Shire) \\
\hline & & Elvanse $^{\circledR}$ (lisdexamfetamine; Shire) \\
\hline & & LiquADD ${ }^{\circledast}$ (dextroamphetamine; Auriga Laboratories) \\
\hline & & Metamina (dexamfetamin) \\
\hline & & Vyvanse $^{\circledR}$ (lisdexamfetamine; Shire) \\
\hline
\end{tabular}

Notes: Intuniv ${ }^{\circledast}$ is approved in the US only; Biphentin ${ }^{\circledast}$ is approved in Canada only; Attentin ${ }^{\circledast}$ is approved in Germany only. Medikinet Retard ${ }^{\circledast}\left(\right.$ not Medikinet $\left.\mathrm{XL}^{\circledR}\right)$ and Equasym Retard ${ }^{\circledR}$ (not Equasym $X L^{\circledR}$ ) are approved in Germany. Equasym $X L^{\circledR}$ is marketed as Metadate $C D^{\circledR}$ in the US.

Abbreviations: ADHD, attention-deficit/hyperactivity disorder; ATX, atomoxetine; GXR, guanfacine extended release; GIR, guanfacine immediate release; CIR, clonidine immediate release; MPH, methylphenidate; AMPH, amphetamine. 


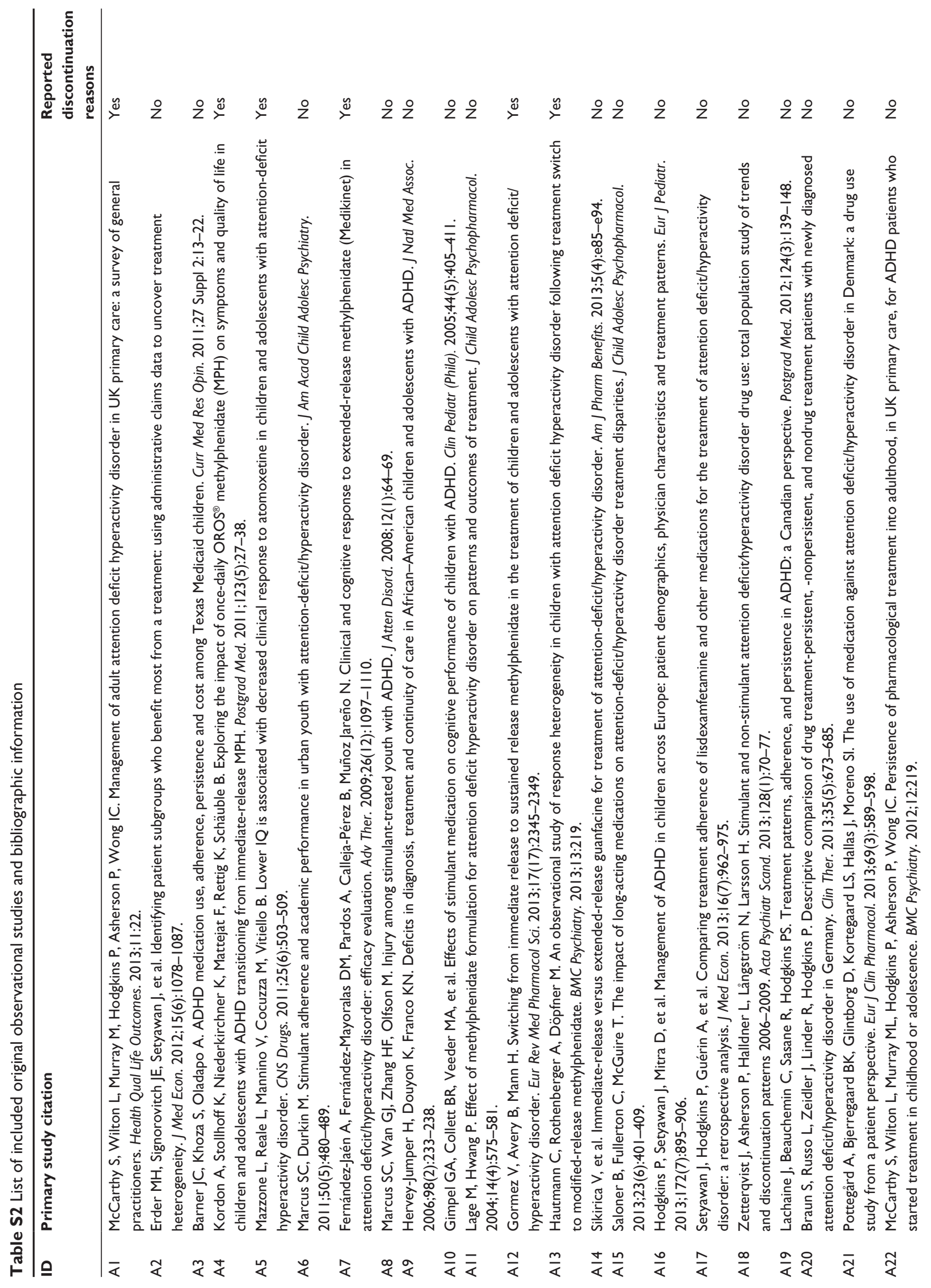




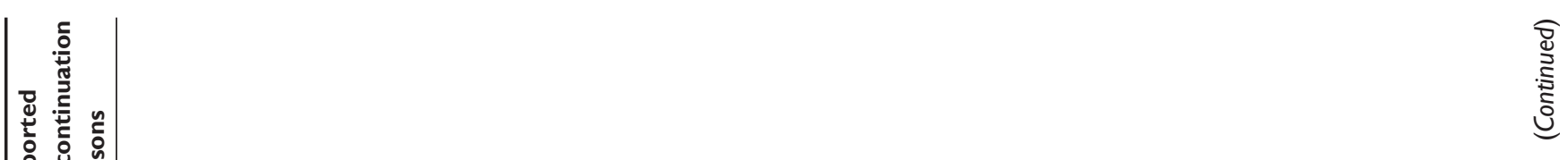

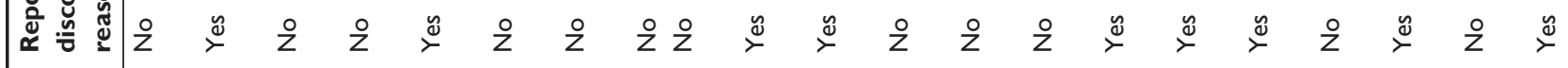

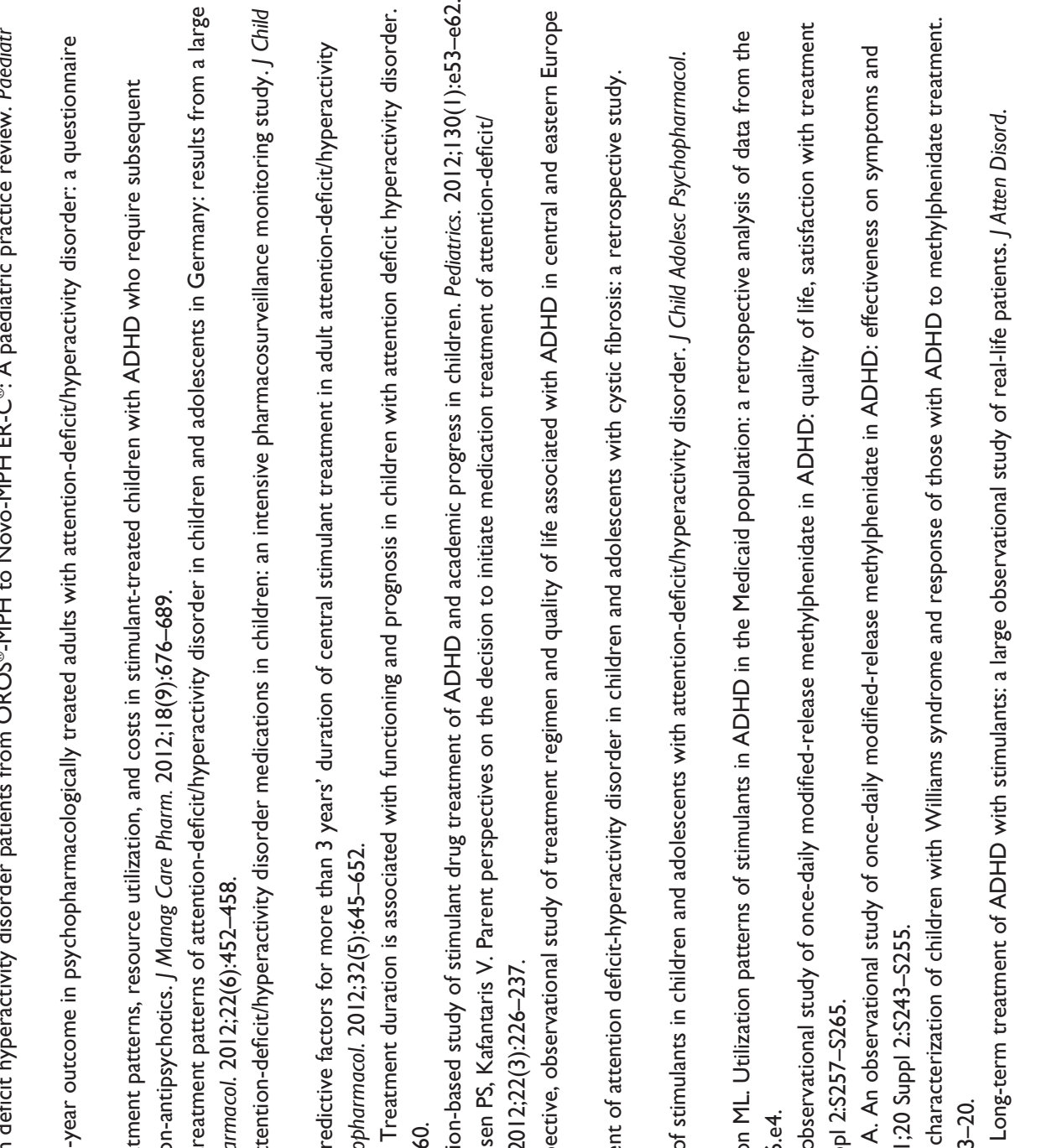




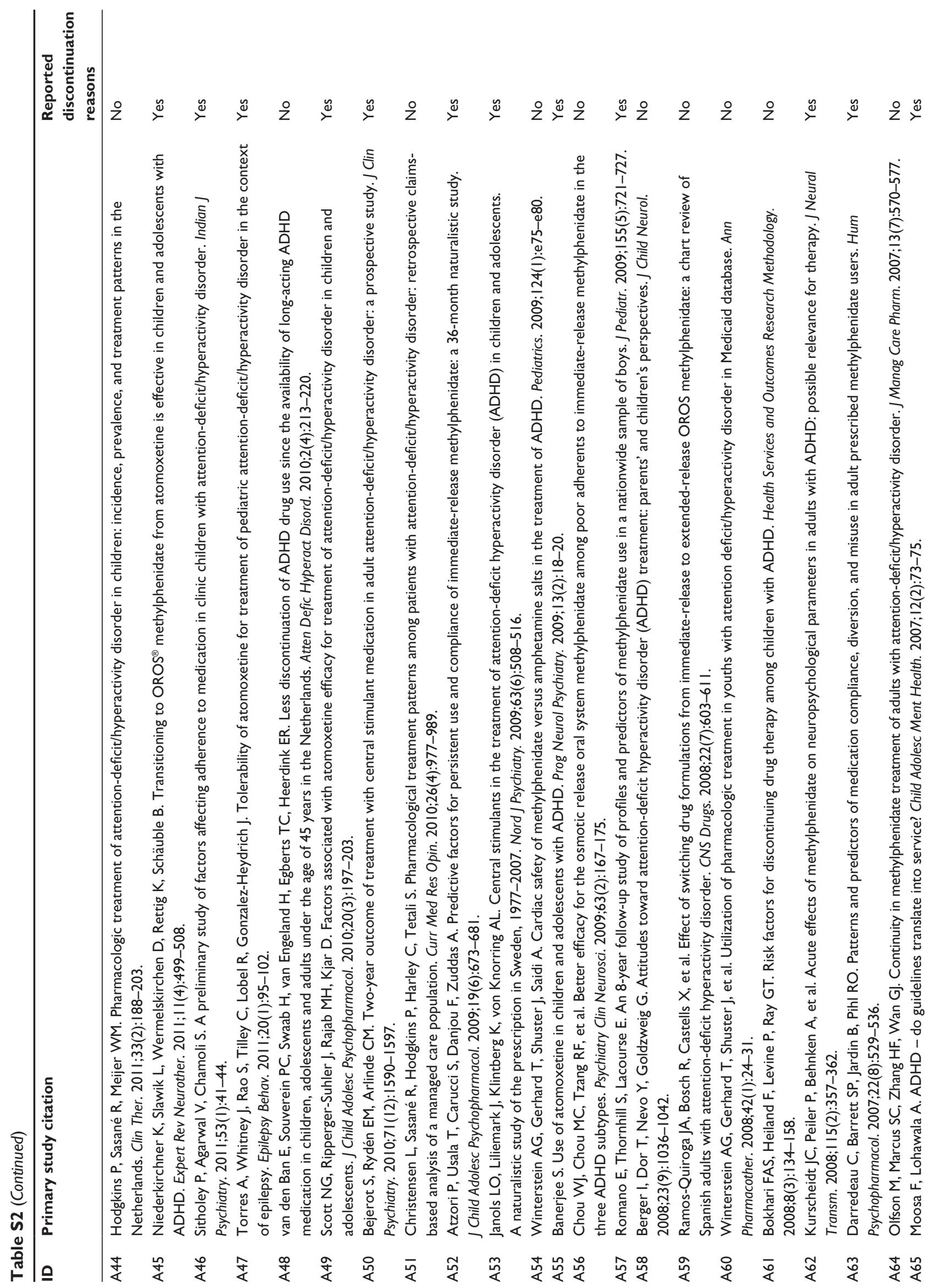




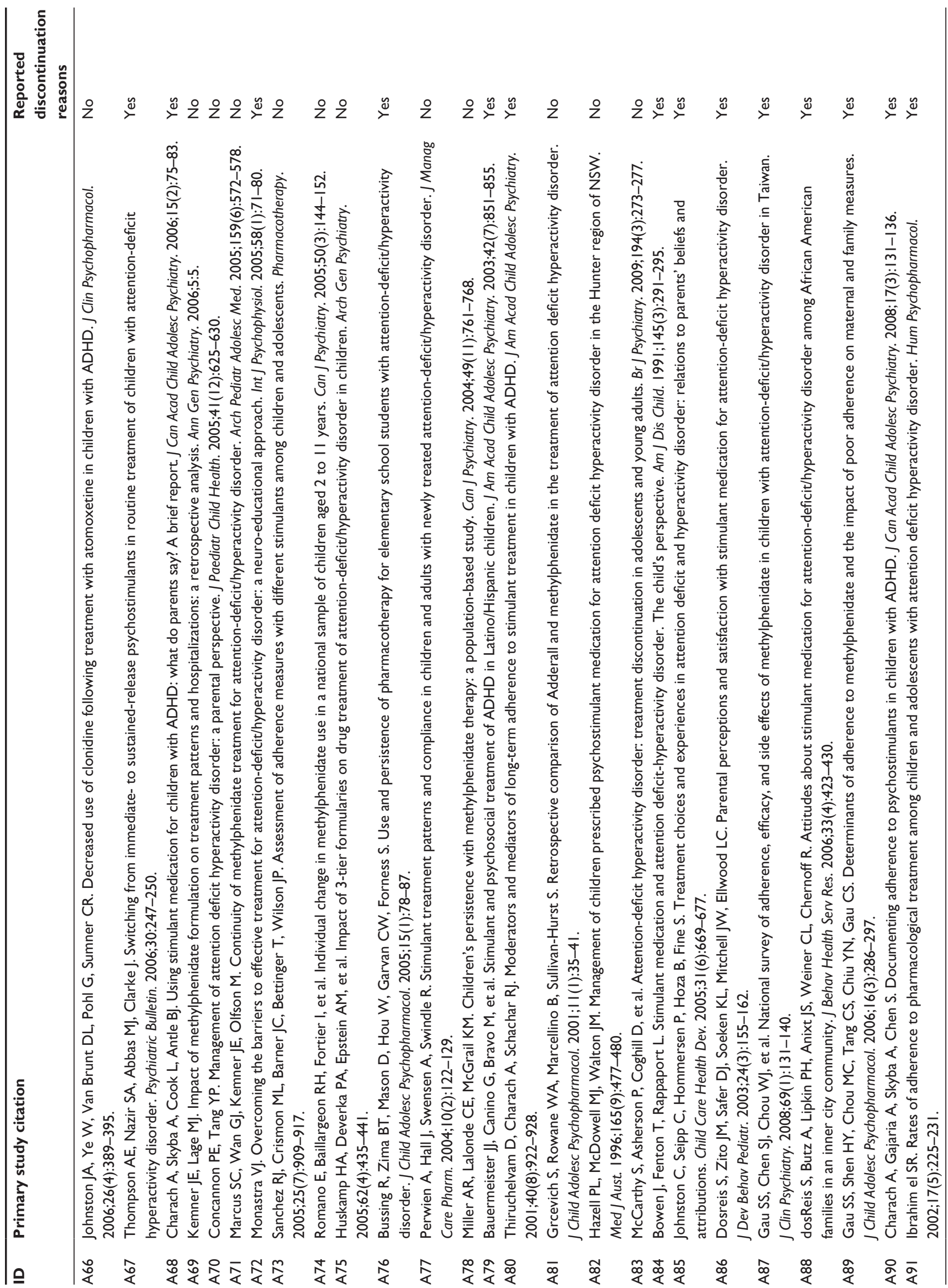




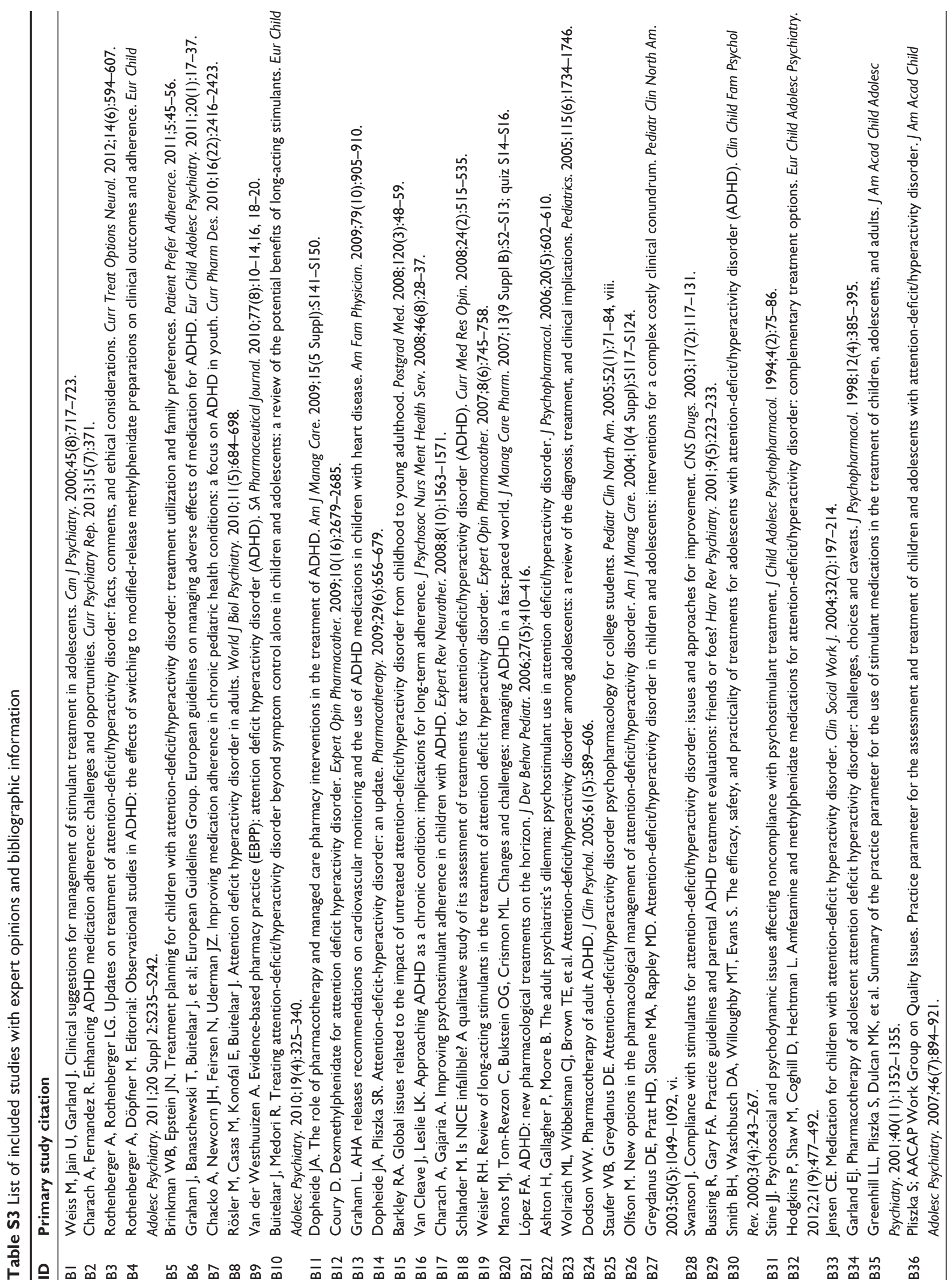




\section{Publish your work in this journal}

Neuropsychiatric Disease and Treatment is an international, peerreviewed journal of clinical therapeutics and pharmacology focusing on concise rapid reporting of clinical or pre-clinical studies on a range of neuropsychiatric and neurological disorders. This journal is indexed on PubMed Central, the 'PsycINFO' database and CAS, and is the official journal of The International Neuropsychiatric Association (INA). The manuscript management system is completely online and includes a very quick and fair peer-review system, which is all easy to use. Visit http://www.dovepress.com/testimonials.php to read real quotes from published authors.

\footnotetext{
Submit your manuscript here: http://www.dovepress.com/neuropsychiatric-disease-and-treatment-journal
} 